NBER WORKING PAPER SERIES

\title{
WHY DIDN'T THE COLLEGE PREMIUM RISE EVERYWHERE? EMPLOYMENT PROTECTION AND ON-THE-JOB INVESTMENT IN SKILLS
}

\author{
Matthias Doepke \\ Ruben Gaetani \\ Working Paper 27331 \\ http://www.nber.org/papers/w27331 \\ NATIONAL BUREAU OF ECONOMIC RESEARCH \\ 1050 Massachusetts Avenue \\ Cambridge, MA 02138 \\ June 2020
}

We thank Marco Bassetto, Samuel Bentolila, Alex Bick, Christian Hellwig, Gueorgui Kambourov, Claudio Michelacci, Moritz Kuhn, Elena Pastorino, Todd Schoellman, Robert Ulbricht, David Wiczer, and participants at many seminar and conference presentations for comments that helped to greatly improve the paper. We gratefully acknowledge financial support from the National Science Foundation (grant SES-1260961). The views expressed herein are those of the authors and do not necessarily reflect the views of the National Bureau of Economic Research.

NBER working papers are circulated for discussion and comment purposes. They have not been peer-reviewed or been subject to the review by the NBER Board of Directors that accompanies official NBER publications.

(C) 2020 by Matthias Doepke and Ruben Gaetani. All rights reserved. Short sections of text, not to exceed two paragraphs, may be quoted without explicit permission provided that full credit, including $(\odot$ notice, is given to the source. 
Why Didn't the College Premium Rise Everywhere? Employment Protection and On-the-Job Investment in Skills

Matthias Doepke and Ruben Gaetani

NBER Working Paper No. 27331

June 2020

JEL No. E24,J24,J31

\begin{abstract}
Why has the college wage premium risen rapidly in the United States since the 1980s, but not in European economies such as Germany? We argue that differences in employment protection can account for much of the gap. We develop a model where firms and workers make relationshipspecific investments in skill accumulation. The incentive to invest is stronger when employment protection creates an expectation of long-lasting matches. We argue that changes in the economic environment have reduced relationship-specific investment for less-educated workers in the United States, but not for better-protected workers in Germany.
\end{abstract}

Matthias Doepke

Northwestern University

Department of Economics

2211 Campus Drive

Evanston, IL 60208

and NBER

doepke@northwestern.edu

Ruben Gaetani

University of Toronto

105 St. George Street

Toronto ON, M5S3E6

(Canada)

ruben.gaetani@rotman.utoronto.ca 


\section{Introduction}

In the United States, the wage gap between workers with and without a college education has risen by more than 30 percentage points since the 1980s (Heathcote, Perri, and Violante 2010). During this period, Canada and the United Kingdom also saw substantial growth in the college wage premium (Krueger et al. 2010). In contrast, the college wage premium has barely changed in a number of continental European economies (Fuchs-Schündeln, Krueger, and Sommer 2010; Jappelli and Pistaferri 2010). In this study, we focus on the particular case of Germany, the largest European economy, where the college wage premium actually fell between 1980 and 2006. Though it did go on to rise slightly, in 2013 the college wage premium was essentially the same as in 1980.

What explains these different trends between otherwise similar countries? Canonical explanations for rising skill premia such as skill-biased technological change (SBTC) do not suggest an immediate explanation, because advanced economies are likely to have comparable exposure to technological shocks. Instead, we focus on the potential role of a factor that does differ sharply between the United States and Europe, namely employment protection. In the United States, most workers are employed at will, meaning they can be dismissed at any time if the employer so chooses. Conversely, labor markets are highly regulated in most European economies, which enact employment protection measures such as firing costs. In Germany, regular employees can only be dismissed for a limited set of reasons. Moreover, German law requires firms who lay off workers to follow a Sozialauswahl (i.e., social criteria) when deciding which workers to dismiss, with special protection given to older workers and those with high tenure. In practice, this means that German workers enjoy considerable protection from layoffs after a few years with a given employer, unless the firm shuts down an entire establishment.

We argue that employment protection matters for the college premium because it affects both firms' and workers' incentives to invest in the relationship. To this end, we develop a quantitative model of the labor market in which on-the-job skill accumulation is a major source of income disparity between workers. Investment in skills is two-sided: firms can decide to create either high-quality jobs that allow for accumulation of skills, or less costly, low-quality jobs in which workers' productivity remains stagnant. Workers with a high-quality job decide how much effort to put into accumulating skills.

The expected length of the employment relationship is an essential consideration in such decisions. Firms and workers will be more inclined to invest in their relationship when they expect more durable matches as a result of employment protection. If, as we argue, 
the skills of college-educated workers are less firm-specific than those of less-educated workers, their skill accumulation decisions will depend less on the expected duration of a given employment spell. Employment protection will thus have a differential impact on the skill accumulation of college-educated and less-educated workers, which is important for the college wage premium.

Our model predicts that the college wage premium will evolve differentially over time between countries with and without employment protection if there is a rise in the frequency of shocks that temporarily depress the productivity of existing firm-worker matches. If such productivity shocks are rare, firms have little reason to dismiss workers and expected job duration is high even without employment protection. Under such conditions, the college premium will be similar in economies with and without employment protection. However, when shocks become more frequent, the duration of employment spells will fall in economies with less employment protection. Firms will have fewer incentives to create high-quality jobs for less-educated workers (whose skills are more job-specific), and these workers will have fewer opportunities to accumulate skills and reduced incentives to acquire them. As a result, the college wage premium will rise. In contrast, the impact of the change will be muted in economies with more employment protection, resulting in little change in the college premium.

We use data from the Panel Study of Income Dynamics (PSID) in the United States and the German Socio-Economic Panel (GSOEP) to verify that observed changes in the job-tenure distribution align with our explanation for shifts in the college premium. We focus on changes in the number of workers who spend most of their working lives with a single firm. Specifically, we measure the fraction of male full-time workers aged 45-54 who have worked for their current employer for at least 20 years. We find that in the early 1980s, the fraction of high-tenure workers in the United States was similar for both moreand less-educated workers: around 42 percent for both groups. The fraction of hightenure workers subsequently declined to about 35 percent in 2010. In Germany, the share of high-tenure workers in 1980 was similar to that of the United States. Subsequently, high tenure declined for college-educated workers but actually increased slightly for less-educated workers. This is exactly what our model predicts should happen in an economy with employment protection in response to a higher frequency of shocks. The different trends between education groups arise because more educated workers (whose skills are more transferable) are able to take their skills to a new employer when a shock hits, whereas less-educated workers rely on employment protection to continue with 
their current employer.

We use our model to assess the quantitative importance of on-the-job investment for changes in the college wage premium. In a first exercise, we calibrate the model to match a number of data moments from the United States in 1980 that include the college wage premium, returns to experience, returns to tenure, and the job-tenure distribution by education. We then allow a number of model parameters to change to match the shifts in these data moments by the year 2010. In addition to the on-the-job investment channel (triggered by a changed frequency of match-specific productivity shocks), the changes we introduce into the model also include other factors such as shifts in overall skill bias or returns to experience, which represent forces such as SBTC or variations in the relative supply of more- and less-educated workers. A decomposition exercise shows that the on-the-job investment channel can account for a large fraction of the rise in the college premium in the United States: up to 36.5 percent in our preferred calibration. Most of this change is due to a decline in the creation of high-quality jobs for less-educated workers.

We also compare the trends in the college wage premium among various cohorts in our model compared to the data during the transition path. The model output coincides with the observation that the college premium rose primarily among younger workers from 1980 to 1990, whereas the pattern had reversed by 2010, with a larger college premium among older workers compared to 1980 in that year (Card and Lemieux 2001). These observations on the transition path were not targeted, yet our model matches them well. The final step of our analysis examines the role of employment protection by considering the case of Germany. In our model exercise, we take the position that Germany is subject to the same technological forces as the United States, but has a different regime of employment protection. We introduce employment protection in the form of a firing cost that increases with job tenure. We set the level of the firing cost to match observations of the share of high-tenure workers in Germany. Then, we ask how this more protected economy reacts to the same shocks that we introduced in our quantitative exercise for the United States. We find that the increase in the college wage premium is almost halved compared to the economy without firing restrictions. We conclude that the combination of differences in employment protection and the on-the-job investment channel can go a long way in explaining the different trends in the college wage premium between the United States and Germany.

Our analysis has implications for the welfare consequences of imposing employment protection. The quantitative model includes a number of frictions that may lead to 
inefficient job-creation and skill-investment decisions, including frictional labor markets, wage rigidities, and a lack of firms' and workers' ability to commit to long-term contracts that are contingent on skill investment. Given these frictions, we find that moderate firing restrictions can indeed improve welfare, primarily because they induce firms to create relatively more high-quality jobs that allow for the accumulation of skills.

The finding on the positive welfare effects of employment protection is, however, sensitive to specific assumptions on frictions in the wage-setting process, which are difficult to pin down precisely with existing evidence. Clearly, labor protection can also have negative repercussions, such as lower job creation and higher unemployment (see, e.g., Bentolila and Bertola 1990). Thus, our analysis does not provide an unqualified argument in favor of more protection. Nevertheless, we believe that the channel identified in our model is important for evaluating the full consequences of employment regulations such as those now in place in Germany and many other advanced economies.

The following section relates our work to the existing literature on the college wage premium and the effects of labor regulation. In Section 3, we describe the main empirical patterns that motivate this study, including new findings on shifts in the number of workers with high job tenure in the United States and Germany. Our quantitative model is described in Section 4, and in Section 5 we explain how we calibrate the model to the data. In Section 6 we describe our results, and Section 7 concludes.

\section{Relationship to Literature}

The best-known explanations for the upward trend in the college wage premium in the United States include factors such as SBTC and trade liberalization (Katz and Murphy 1992; Katz and Autor 1999; Krusell et al. 2000; Autor, Levy, and Murnane 2003; Goldin and Katz 2008; Guvenen and Kuruscu 2009; Jaimovich et al. 2019). The authors who propose these explanations take the view that workers with higher education have benefited disproportionately from the technological and institutional shifts that have occurred since the 1980s. Our quantitative analysis allows for factors that increase the productivity of highly educated workers, and we do find that these factors play a significant role.

Nevertheless, the on-the-job investment channel that we propose focuses primarily on the skills of less-educated workers, and implies that such workers currently have fewer opportunities for accumulating skills than in the past. This channel is consistent with new evidence on the recent deterioration of the labor market opportunities of less-educated 
workers, a trend that directly contributes to increased inequality between education groups (Autor 2019). Deteriorating outcomes for less-educated workers are evidenced in stagnating income levels even as aggregate productivity keeps growing (Guvenen et al. 2017), in worsening measures of job quality and security (Segal and Sullivan 1997; Hollister 2011), and in other indicators of economic well-being (Coile and Duggan 2019). Our analysis proposes a specific mechanism that can explain the increasing scarcity of "good jobs" for less-educated workers.

Alternative explanations for the deterioration of labor market outcomes for less-educated workers include automation and robotization (Hémous and Olsen 2018, Acemoglu and Restrepo 2020), job polarization (Autor and Dorn 2013), and exposure to trade (Autor, Dorn, and Hanson 2013). More closely related to our analysis, Acemoglu (1999) develops a model in which changes in macroeconomic conditions generate a shift in the type of jobs offered by firms. In his setting, as the supply of skilled workers increases, firms transition from a pooling equilibrium with similar jobs offered to all workers to a separating equilibrium in which jobs are specific to each skill type, which benefits educated workers but harms the less educated.

The studies mentioned thus far do not, however, offer an explanation for why trends in wage inequality have progressed differently in the United States and European countries such as Germany. Among the earlier contributions on this specific issue, Acemoglu (2003) does focus on the potential role of more regulated labor markets in Europe. Specifically, based on Acemoglu and Pischke (1999b), he develops a mechanism by which a high minimum wage may lead firms to adopt productivity-enhancing technologies for lesseducated workers. Intuitively, if the minimum wage is initially binding but no longer applies when the technology is adopted, investing in the technology increases the firm's share of the surplus, which raises the incentive to invest relative to firms in a less regulated labor market. While related, this specific mechanism is less likely to be relevant for Germany, where minimum wages were introduced only a few years ago.

Guvenen, Kuruscu, and Ozkan (2013) develop a mechanism complementary to ours, arguing that increasingly progressive taxation lowered European workers' incentives to invest in their skills, thus compressing the skill distribution relative to the United States and lowering observed skill premia. While they similarly concentrate on the accumulation of skills on the job, their primary focus is the top of the skill distribution, whereas our model deals mainly with less-educated workers. This focus is shared with Alon (2017), who argues that features such as apprenticeship programs in Germany pro- 
vide less-educated workers with differentiated skills, whereas investment in vocational training for less-educated workers in the United States has decreased over time, leading to a deterioration of skills in this group. This mechanism is also complementary to ours, as it concentrates on the initial acquisition of skills by more- and less-educated workers, whereas our model is concerned with investments in on-the-job skills acquisition. One advantage of the employment-protection mechanism developed in our study is its distinct implications for the tenure distribution and returns to tenure in different education groups, which can be empirically tested.

Our work also contributes to a literature on the macroeconomic consequences of differences in labor regulation between the United States and European economies. In particular, we build on Ljungqvist and Sargent (1998), who similarly develop a mechanism by which differences in labor regulation interact with changes in the economic environment. However, they consider entirely different policies, outcomes, and economic shifts; specifically, the impact of unemployment insurance on unemployment levels. Other contributions that focus on unemployment include Blanchard and Summers (1986), Bertola and Ichino (1995), Nickell (1997), Hornstein, Krusell, and Violante (2007), and Kitao, Ljungqvist, and Sargent (2017). Our paper adds a new angle to this literature by arguing that the level of employment protection has repercussions for education premia in the labor market.

In addition, our analysis is related to the literature on on-the-job investment in skills and the distinction of general versus firm-specific skills. There are a variety of reasons why investment in skills on the job may fail to be efficient; see Acemoglu and Pischke (1999a) for a discussion. We build, in particular, on the analysis by Wasmer (2006) of investment in general versus firm-specific skills in a frictional labor market. Wasmer argues that search frictions make investing in general skills less attractive, because such skills pay off relatively more in future matches with other firms, which are harder to find if there are search frictions. Similarly, employment protection makes job-specific skills more attractive. The link between employment protection and investment in specific skills is also central to our mechanism. However, Wasmer's analysis does not extend to the implications for the college wage premium and cross-country inequality trends.

Finally, our empirical findings on shifts in the job-tenure distribution are relevant to a recent literature on reduced dynamism in the US labor market. At first sight, this literature may appear to contradict our finding of declining rates of high tenure. For example, Hyatt and Spletzer (2016) document that average job tenure has risen in the 
United States since 1980, as has the fraction of workers with at least 5 years of tenure. These observations can be reconciled by noting that part of the shift towards higher tenure is due to population aging. Furthermore, there has been a shift towards reduced churn at the beginning of employment spells, decreasing the fraction of workers with very low job tenure. The facts we document here become apparent only when focusing on the share of older workers with very high tenure (15 years or above), whereas most papers that consider the share of high-tenure workers use a threshold of 10 years of tenure. Molloy, Smith, and Wozniak (2019) document changes in the entire tenure distribution for the United States and find, as we do, that the share of older workers with high tenure has declined. In our quantitative model, we include an additional churn shock that destroys a proportion of recently created matches to generate an overall tenure distribution that matches the data.

\section{The College Premium, Long-Term Tenure, and Returns to Tenure in the United States and Germany}

In this section, we document the empirical facts that motivate our study and which our quantitative model aims to account for. We focus on the evolution of key labor market variables in the United States and Germany since the early 1980s. To this end, we employ the 1981-2013 waves of the Panel Study of Income Dynamics (PSID) for the United States, and the 1984-2013 waves of the German Socio-Economic Panel (GSOEP) for Germany. ${ }^{1}$ These data sets provide individual-level information on job tenure, wages, and education, allowing us to perform a comparative analysis of the US and German experiences. We focus on men aged 25 to 64 with at least a high school education. ${ }^{2}$ In the German data, we focus on the original sample of the GSOEP (which only includes families in West Germany), so that results are not influenced by the different work histories of East German men that were sampled after reunification. We also construct a system of weights that keeps the age distribution by education fixed with respect to the first year of the sample (1981 for the PSID and 1984 for the GSOEP). All the statistics in this section are constructed using this system of weights. Appendix A contains details on sample selection and the construction of the main variables for the analysis.

\footnotetext{
${ }^{1}$ The PSID was collected every year until 1997, and every other year from 1997 onwards. 1984 was the first wave of the GSOEP.

${ }^{2}$ We limit our attention to men because changes in women's job tenure over this period were dominated by the large shifts in female labor force participation that occurred during this period.
} 


\subsection{Education Premia and the Share of College Graduates in the United States and Europe}

As widely documented by the existing literature (Heathcote, Storesletten, and Violante 2010), the US economy has witnessed a sharp rise in the college wage premium since the 1980s. The solid line in the top panel of Figure 1 displays the college wage premium trend in the United States from 1981 to 2013, obtained by regressing log real wages on a college education dummy and computing the trend component using a Hodrick-Prescott filter. The estimated trend displays a sharp increase starting in the early 1980s, leading to a peak at almost twice the original value in the mid-2000s and stabilizing thereafter (Valletta 2016).

This increase in the returns to education coincided with a contemporaneous rise in the relative supply of college-educated workers. The solid line of the bottom panel of Figure 1 shows the changing share of college graduates among US male workers starting in 1981, revealing a steady upward trend from 36 percent in 1981 to 45 percent in 2013.

Beginning with studies by Katz and Murphy (1992), Krusell et al. (2000), and Acemoglu (2002a), a sizeable literature has rationalized the contemporaneous increase in the market price and the relative supply of skilled workers in the United States by suggesting that technological advancements in recent decades have disproportionately favored college-educated workers. Yet this explanation for the issue at hand is limited in that all industrialized countries use similar technologies and have also experienced a similar rise in the supply of college-educated workers, but patterns in the college wage premium vary widely.

Germany is a case in point. The relative labor supply of college-educated workers in Germany closely tracks US trends, but Germany did not see a comparable increase in the college wage premium. The dashed line in the top panel of Figure 1 shows that the college wage premium was similar in Germany and the US in the early 1980s, but it subsequently rose in the United States while remaining flat in Germany.

The different trends for the college wage premium suggest that country-specific factors have a substantial impact on the college premium in addition to skill-biased technical change. Our study is motivated by the observation that changes in the education premium across countries are empirically correlated with measures of labor protection. Figure 2 plots the percentage change in the college premium between 1980 and 2006 in a sample of OECD countries against the OECD labor protection index. The graph 

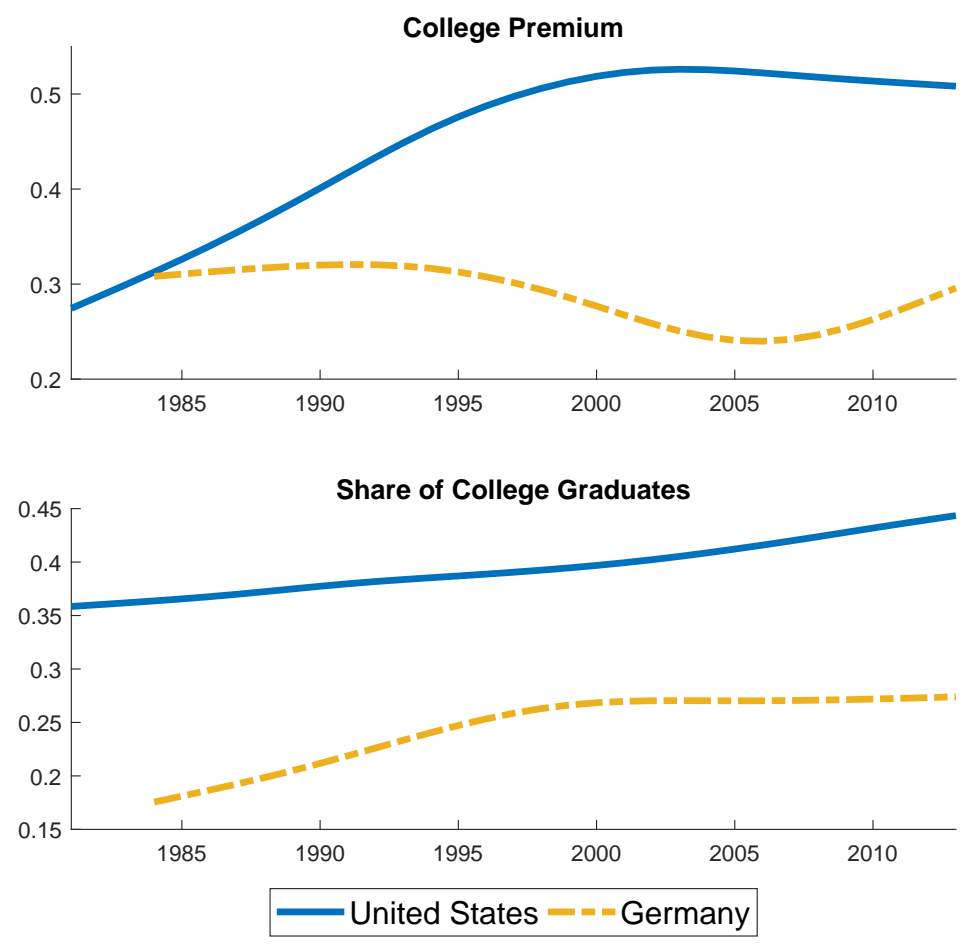

Figure 1: Top panel: The college wage premium in the United States and Germany among workers aged 25-64, 1981 to 2013. Bottom panel: Share of college graduates among workers aged 25-64, 1981-2013. The series represent five-year moving averages around the focal year, smoothed using a Hodrick-Prescott filter with a smoothing parameter equal to 100 .

shows a strong negative correlation between growth in the college wage premium and the labor protection index. Among the countries plotted, the United States has the leastregulated labor markets and the fastest rise in the college wage premium. At the other end of the scale, Germany, Italy and Spain-all countries with high levels of employment protection-actually experienced a decline in the college wage premium over the same period.

While this is a simple correlation and not necessarily a causal relationship, it motivates our analysis of a channel through which employment protection can impact changes in the college premium. Specifically, we argue that employment protection can increase the incentives for workers and firms to make relationship-specific investments that pay off if workers stay with the same firm for a long time. For workers, these investments take the form of the costly acquisition of firm-specific skills. For firms, they take the form of the creation of jobs that utilize such firm-specific skills and allow workers to acquire 


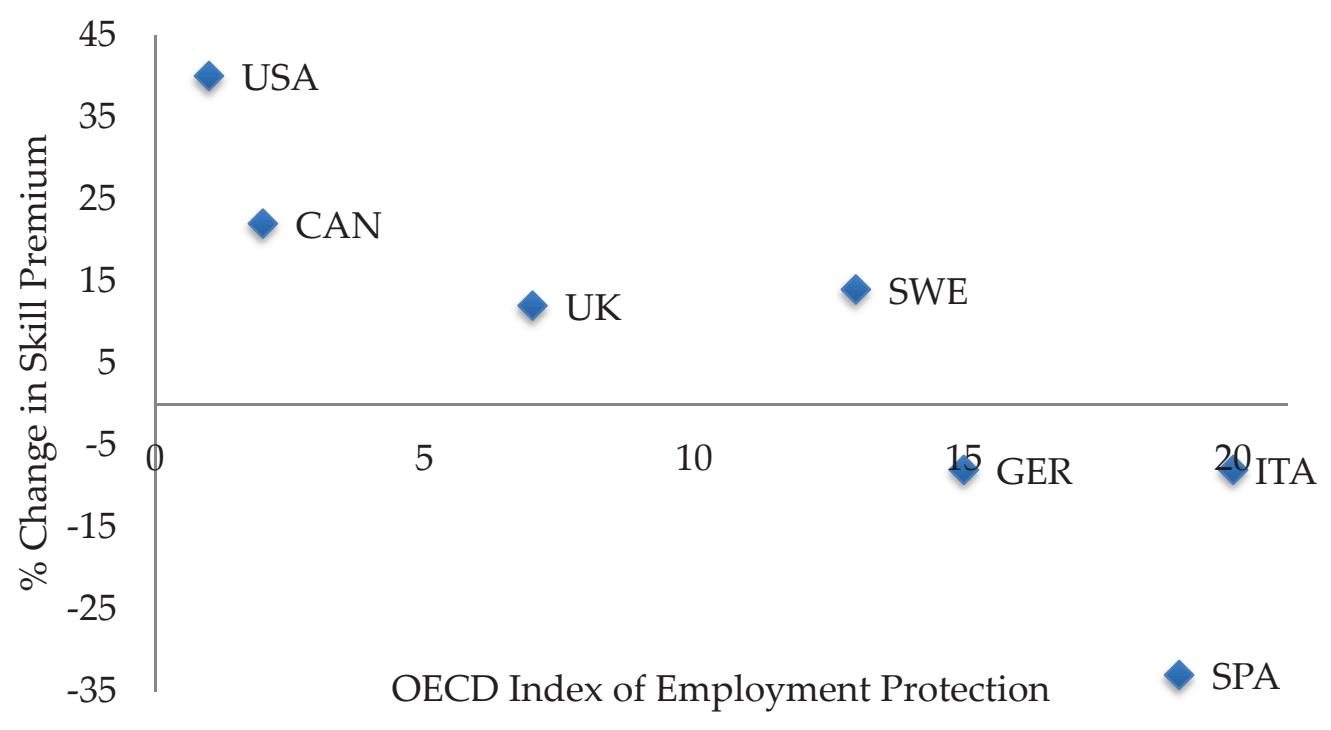

Figure 2: Labor protection in the early 1990s and the change in the education premium from 1980 to 2006. Data from Krueger et al. (2010) and Nickell (1997).

them. In our model, if worker-firm matches are subject to frequent productivity shocks, employment protection can lead to an expectation of a longer duration of matches, which in turn increases the incentive to invest in the relationship. The employment-protection mechanism links changes in skill premia in the labor market to shifts in employment duration for different groups of workers. We show that this connection is supported by evidence from the United States and Germany.

\subsection{The Fall in Long-Term Tenure}

The link between employment regulation and the evolution of wage premia that we propose in this paper relies on the notion that workers in economies with more employment protection experience less job turnover and hence are more likely to achieve long-term tenure with a given employer. The PSID and the GSOEP data sets can be used to verify whether this is actually the case.

We focus on the share of workers aged 45 to 54 who have been with their current employer for at least 20 years, a group we term "long-term tenure" workers. Such workers have spent most of their working lives with their current employers, and are therefore especially likely to benefit from relationship-specific investments. Figure 3 displays the changing share of long-term tenure workers in the United States and Germany from the 1980s to the 2010s, charted separately for college graduates and less-educated workers. In the United States, this share displays a clear downward trend for both education groups, 
declining from about 42 percent in 1981 to about 35 percent in $2013 .^{3}$

The pattern for less-educated workers in Germany is strikingly different. While their long-term tenure share is only slightly above the US level in 1984, there is no clear downward trend in the following decades. The long-term tenure share first increases substantially and then falls, returning to 1984 levels by 2013 .

The US-Germany difference in less pronounced among college-educated individuals (Figure 3, bottom panel), whose share of long-term tenure workers declines in both countries. Our quantitative model accounts for this pattern by assuming that collegeeducated workers have skills that are more transferable from one employer to another. This implies that these workers are more likely to end up with a new employer in response to match-specific shocks, even in economies with stringent labor market policies. Put differently, labor protection has non-uniform effects for workers with more or less transferable skills.

The trends in Figure 3 remain if we exclude public-sector workers. Specifically, excluding public-sector employment does somewhat reduce the share of workers with high tenure in both countries, consistent with higher job security for public-sector workers, but does not change the general trends over time.

\subsection{Returns to High Tenure for High School and College Graduates}

The employment-protection mechanism relies on the presumption that the skills of college graduates are more transferable between employers, meaning that their skill investment is less affected by shocks that destroy long-lasting firm-worker matches. In our model, differential transferability of skills results in less-educated workers having higher returns to job tenure (i.e., the time worked at their current employer), whereas more-educated workers have low returns to tenure but high returns to experience (the overall time worked in the labor market across all employers). These patterns are supported by recent findings in the empirical labor literature on returns to experience and job tenure.

Measuring returns to job tenure is complicated by possible selection bias: more skilled workers may be more likely to be retained by the employer and achieve high tenure, meaning that observed returns could partially reflect workers' ability. Altonji and Shakotko (1987) argued that selection accounts for most of the empirical correlation of job tenure and wages. However, this conclusion has been revised by Altonji and Williams (2005),

\footnotetext{
${ }^{3}$ The substantial share of high-tenure workers in earlier US data is also noted by Hall (1982).
} 

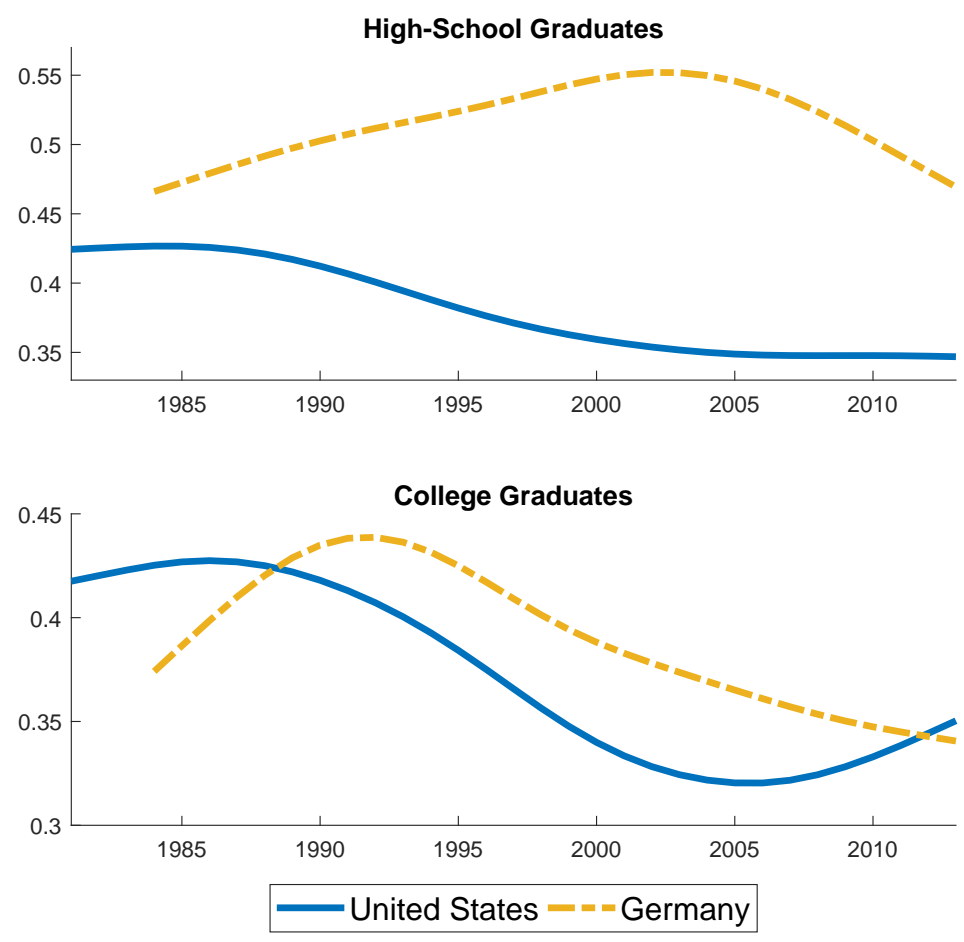

Figure 3: Share of workers aged 45-54 with tenure of over 20 years at their current employer in the United States and Germany, 1981-2013. Top panel: High-school graduates. Bottom panel: College graduates. The series represent five-year moving averages around the focal year, smoothed using a Hodrick-Prescott filter with smoothing parameter equal to 100 .

among others, who do find substantial returns to tenure. Buchinsky et al. (2010) address the relationship between education and returns to tenure in the United States, demonstrating that less-educated workers (especially workers with less than a high school education) have higher returns to tenure and lower returns to experience than do college-educated workers, which is the assumed pattern in our model. Studies that use events such as mass layoffs to estimate the firm-specificity of human capital reach similar findings. For example, Kletzer (1989) shows that blue-collar workers suffer large losses of accumulated returns to job tenure after displacement, whereas managerial, professional, and technical workers are much less affected ${ }^{4}$. To the extent that less-educated workers are more likely to be blue-collar workers, these findings align with our analysis.

\footnotetext{
${ }^{4}$ In an overview of the job displacement literature, Kletzer (1998) characterizes the evidence as follows: "The far larger dropoff in the contribution of predisplacement tenure to postdisplacement earnings for blue-collar workers reveals the importance of factors such as specific human capital and job match effects for these workers. In contrast, individual ability and transferable skills are a more important part of the returns to tenure for the skilled white-collar group."
} 


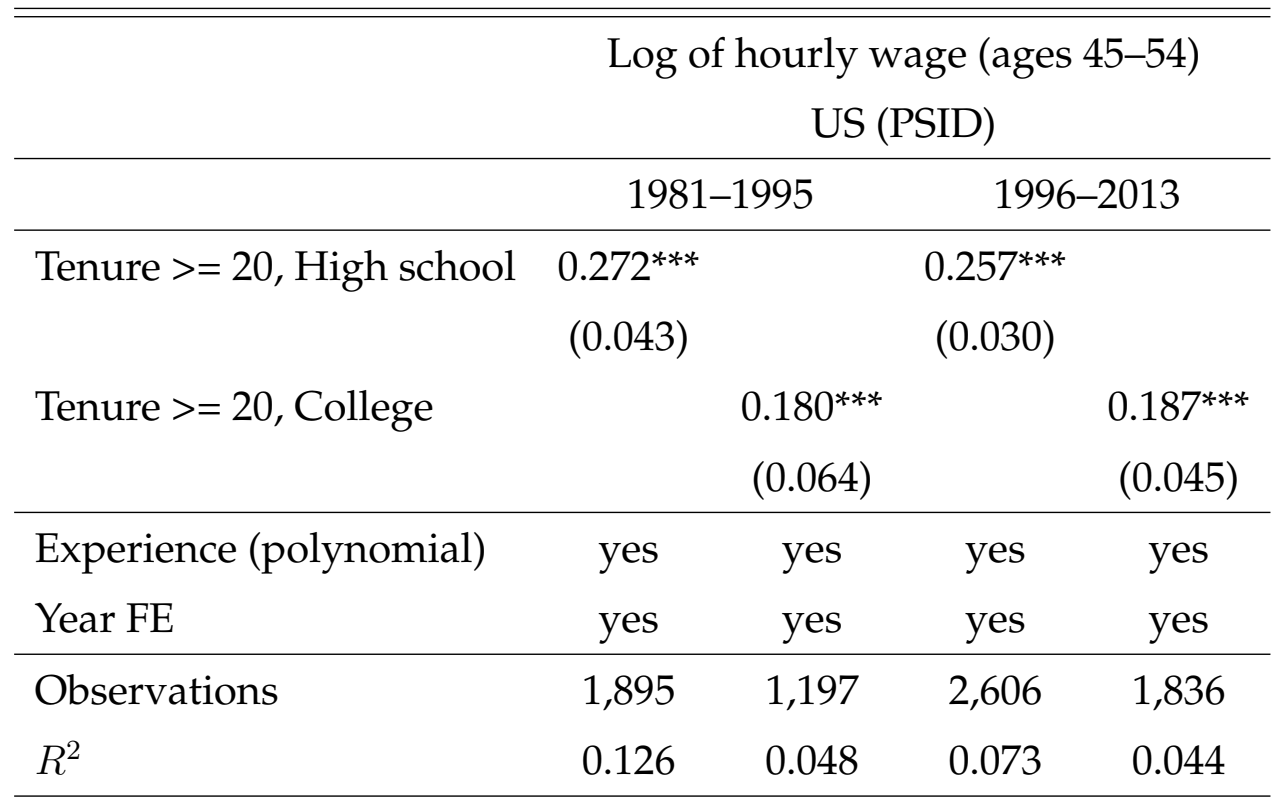

Notes: Standard errors in parentheses. Standard errors are clustered at individual level. The sample consists of male workers aged 45 to 54 who report between 500 and 5,000 hours worked in a year. Each column consists of a separate regression of $\log$ wages on a year fixed effect, a third-degree polynomial of potential experience, and an indicator variable for 20 years of tenure or more on the current job. ${ }^{* * *} \mathrm{p}<0.01,{ }^{* *} \mathrm{p}<0.05,{ }^{*} \mathrm{p}<0.1$.

Table 1: Returns to high tenure for college- and less-educated workers in the United States

Dustmann and Meghir (2005) use German firm closure data for identification to examine returns to tenure and experience. They document that the least-educated workers have low returns to experience but substantial returns to firm-specific tenure, also in line with the employment-protection mechanism.

One question that remains unsettled is why less-educated workers have higher returns to job tenure. It may be that the tasks performed by less-educated workers are indeed more firm-specific and less transferable across employers. Another possibility is that the accumulation of skills is primarily occupation-specific, and that less-educated workers are more likely to be displaced from their current occupation after a job loss. This distinction may have important policy implications. That said, for our objective of explaining changes in the college wage premium, all that matters is that returns to job tenure differ by education.

For the purposes of our quantitative analysis, we must ensure that our model incorporates a quantitatively plausible gap in the returns to high job tenure for college- and less- 
educated workers. We therefore compute empirical returns to high job tenure based on PSID data for the United States and GSOEP data for Germany. To ensure consistency with our earlier analysis of high-tenure workers, we focus on the returns to working with a given employer for at least 20 years. Table 1 reports the estimated coefficients of individual-level regressions of log-hourly wages on a set of year fixed effects, a thirddegree polynomial of potential experience, ${ }^{5}$ and a dummy variable that is one if the worker has been with the same employer for at least 20 years. We run these regressions on the sample of male PSID respondents aged 45 to 54 who report at least 500 hours of yearly employment. We compute the returns to high tenure separately for workers with a high school and college education, ${ }^{6}$ and also split the sample into an early (1981-1995) and late period (1996-2013) to assess whether returns to high tenure change significantly over time. In line with the literature, the estimated coefficients show that returns to high tenure are much smaller for college educated workers. The change between the early and late period is fairly small: workers with high tenure have a substantial pay advantage in both periods, though there are considerably fewer such workers by the late period (Figure 3).

Table 2 reports the results of an analogous set of regressions performed on the German GSOEP sample. The average measured returns to high tenure are smaller than in the US data, but the gap between more- and less-educated workers is similar. Patterns are also similar between the earlier and the later periods.

To further validate the patterns reported in Tables 1 and 2, we run separate pooled regressions on the PSID and GSOEP samples that include all workers aged 45 to 54 and regress the log-hourly wage on a set of year fixed effects, college attainment, and long-term tenure dummy variables, as well as the interaction between the latter two. The results are reported in Table 12 in the appendix. The coefficients of the interaction terms are negative, consistent in magnitude, and statistically significant in both samples. The size of the estimates implies that the premium enjoyed by high-tenure workers with a high-school education is 10.7 percentage points higher than that for college-educated workers in the United States, and 16.6 percentage points higher in Germany.

It is important to recognize that the results in Tables 1 and 2 do not control for selection effects and therefore should not be interpreted as estimates of the causal effect of high

\footnotetext{
${ }^{5}$ We define potential experience as current age minus (years of education +6 ).

${ }^{6}$ Individuals with some college education who have not completed a four-year tertiary degree are counted as high-school graduates.
} 


\begin{tabular}{lcccc}
\hline \hline & \multicolumn{3}{c}{ Log of hourly wage (ages 45-54) } \\
Germany (GSOEP)
\end{tabular}

Notes: Standard errors in parentheses. Standard errors are clustered at individual level. The sample consists of male workers aged 45 to 54 who report a minimum of 20 hours worked per week in the last year. Each column consists of a separate regression of $\log$ wages on a year fixed effect, a third-degree polynomial of potential experience, and an indicator variable for 20 years of tenure or more on the current job. ${ }^{* * *} \mathrm{p}<0.01,{ }^{* *} \mathrm{p}<0.05,{ }^{*} \mathrm{p}<0.1$.

Table 2: Returns to high tenure for college- and less-educated workers in Germany

tenure on wages. Rather, we view these regressions as data moments that a quantitative model of on-the-job skill accumulation should be able to match. Like the data, our model is subject to selection effects, because initial skill and luck in skill upgrading affect the likelihood of reaching high tenure. In our quantitative analysis below, we discipline the model to generate the observed empirical link between high tenure and wages, which includes both selection and skill-accumulation effects. Crucially, however, the quantitative exercise is less concerned with the level of returns to high tenure (where selection is likely to matter more) than the gap in empirical returns between more- and less-educated workers.

\section{A Labor Search Model with Skill Upgrading}

In this section, we develop a quantitative model of job creation and on-the-job accumulation of human capital that can account for the facts described in Section 3. The key elements of the model are a life-cycle structure and relationship-specific investments by both firms and workers. Firms decide to create jobs that either do or do not allow 
for the accumulation of skills. If they have a job that allows for skills accumulation, workers decide how much effort to invest in acquiring skills. The incentives to undertake these two-sided investments depend on the expected length of the firm-worker relationship which, in turn, is determined by the economic environment and by the extent of employment protection.

\subsection{Demographics and the Labor Market}

Every year, a new cohort of workers enters the labor market. Workers' education $e$ is heterogenous, with $e=H$ denoting a college education and $e=L$ a lower level of education. A cohort enters the labor market at age 25 and retires at age 65. Workers are risk neutral and discount future periods with a yearly discount factor $\beta<1$. A worker's instantaneous utility is given by consumption minus the cost of effort $z$ exerted to acquire skills on the job. After retirement, workers' continuation utility is independent of their skill accumulation. The continuation utility therefore does not affect decisions and is normalized to zero. Each worker is characterized by a productivity level $h$ on a skill ladder, $h \in\left\{h_{1}, \ldots, h_{I}\right\}$. When workers enter the labor market at age 25, their initial productivity is drawn from a distribution $F(h)$.

Unemployed workers are matched with a firm with probability $\lambda$ every period. ${ }^{7}$ Firms create vacancies for either college-educated or less-educated workers. If the vacancy is for less-educated workers, the firm also has to decide whether to make an investment such that the created job allows the worker to accumulate skills (type- $A$ job), or to forgo this investment such that no skills can be accumulated (type- $N$ job). Jobs for college-educated workers are always of type $A$. The type of a job is denoted by $p \in\{A, N\}$.

Jobs that allow for skill accumulation are more profitable, but also more costly to create. There is heterogeneity across firms with respect to the cost of creating an accumulationtype job, which makes the supply of these jobs responsive to relative profitability. Specifically, after creating the vacancy, the firm draws the investment cost $k$ from a uniform distribution with limits $\left[c_{0} E\left[J_{N}^{L}\right], c_{1} E\left[J_{N}^{L}\right]\right]$, where $c_{1}>c_{0}>0$ and $E\left[J_{N}^{L}\right]$ is the expected profitability of $N$-type jobs. ${ }^{8}$ This investment represents the cost of creating an

\footnotetext{
${ }^{7}$ We use an exogenous job-finding rate because there is little variation in unemployment across the periods and countries that we compare in the quantitative exercise, and explaining unemployment is not the focus of our analysis. However, it would be straightforward to endogenize the job-finding rate in the usual way through a matching function.

${ }^{8}$ We use a uniform distribution because our quantitative results depend primarily on the fraction of type- $A$ jobs and on how strongly this number varies with relative profitability, which pins down the two
} 
accumulation-type job. Scaling the distribution by the factor $E\left[J_{N}^{L}\right]$ guarantees that proportional shifts to the profitability of all jobs (say, through an increase in overall productivity) do not affect the fractions of type- $A$ and type- $N$ jobs created.${ }^{9}$ Given this cost, the firm will open a type- $A$ vacancy if and only if the cost $k$ is lower than the difference between the expected returns from the two types of vacancies:

$$
k \leq E\left[J_{A}^{L}\right]-E\left[J_{N}^{L}\right]
$$

Hence, the share $\nu_{A}^{L}$ of type- $A$ jobs will be equal to:

$$
\nu_{A}^{L}=\min \left\{\max \left\{\frac{E\left[J_{A}^{L}\right]-E\left[J_{N}^{L}\right]}{\left(c_{1}-c_{0}\right) E\left[J_{N}^{L}\right]}-\frac{c_{0}}{c_{1}-c_{0}}, 0\right\}, 1\right\} .
$$

Equation 1 illustrates that the share of jobs for $L$ workers that allow for accumulation of skills is an increasing function of the relative expected profitability of the two types of jobs, $E\left[J_{A}^{L}\right] / E\left[J_{N}^{L}\right]$.

\subsection{Production and Turbulence Shocks}

Once worker and firm are matched, they start producing. Under normal conditions, a match between a firm and a worker of education $e$, skill level $h$, and potential experience $x$ (where $x=1$ at age 25 and $x=40$ at age 64) produces output $y^{e}(x, h)=a^{e}(x) h$. For a given match, this initial output level changes over time for two reasons: a change in the experience profile $a^{e}(x)$ or a change in skill $h$, provided that the job type allows for the accumulation of skills. The term $a^{e}(x)$ captures all sources of life-cycle wage growth that are not due to investment in skill by the worker.

The output level can also be affected by turbulence shocks, which are temporary but persistent decreases in match-specific productivity. New matches in the first period of the firm-worker relationship are not affected by these shocks. Before production takes place in later periods, the match is affected by turbulence with probability $\gamma$. If the shock hits, the match productivity is reduced to a fraction $\epsilon<1$ of regular productivity, where $\epsilon$ is drawn from a distribution $G(\epsilon)$. A match can be subject to multiple turbulence shocks, i.e., subsequent reductions in productivity by a fraction $\epsilon$. A turbulence shock lasts until

parameters of the uniform distribution. Other distributions would give similar results provided that they match the level and slope of the supply of type- $A$ jobs in our calibrated model.

${ }^{9}$ This scaling could arise from the investment requiring an input of unskilled labor; unskilled wages are linked to profits through wage bargaining. 
separation or until productivity returns to the regular level. The probability of the shock being reversed is also given by $\epsilon$ (i.e., the size of the shock), implying that more severe shocks (lower $\epsilon$ ) are more persistent.

In addition to turbulence shocks, the match can also be hit by an irreversible negative shock that permanently reduces match productivity to zero, leading to immediate separation. The probability of this separation shock depends on the worker's tenure at their current job and is denoted by $\theta(t)$, where $t \geq 1$ is tenure. The separation shock allows us to match observed trends in the prevalence of short-duration jobs separately from that in the share of workers with long-term tenure. ${ }^{10}$

\subsection{Skill Accumulation and Skill Loss}

Workers with jobs that allow for human capital accumulation choose how much effort to exert in accumulating skills. A worker with education $e \in\{H, L\}$, experience $x$, and current productivity level $h_{i}$ can exert effort $z$ at $\operatorname{cost} a^{e}(x) h_{i} z^{2}$. If the effort is successful, a worker with skill level $h_{i}$ upgrades their skills to $h_{i+1}$, which happens with probability:

$$
p(z)=\psi \frac{z}{z+1},
$$

where $\psi>0$ is a parameter. We assume that, for given worker characteristics, the effort exerted during regular times does not change when a turbulence shock hits. ${ }^{11}$ Upon separation from any job, workers suffer a downgrading of their skills, so that a worker of education $e \in\{H, L\}$ and skill level $h_{i}$ transitions to skill level $h_{j}$ with probability $Q^{e}(i, j)$. Here $Q^{e}(i, j)=0$ if $j>i$, meaning that separation can never result in higher skills. The $Q^{e}(i, j)$ are defined as follows:

$$
\begin{aligned}
Q^{e}(i, j) & =\sigma^{e} Q^{e}(i, j+1) \text { for } j<i, \\
\sum_{j=1}^{i} Q^{e}(i, j) & =1 .
\end{aligned}
$$

The parameter $\sigma^{e} \geq 0$ captures the job specificity of the accumulated skills. A lower value of $\sigma^{e}$ implies a distribution of $Q^{e}(i, j)$ that first-order stochastically dominates the

\footnotetext{
${ }^{10} \mathrm{~A}$ rich literature has documented a decline in the rate of job turnover that is largely explained by the decline in jobs with a very short duration. See, among others, Hyatt and Spletzer (2016), Pries and Rogerson (2019), and Molloy, Smith, and Wozniak (2019).

${ }^{11}$ This assumption is introduced for computational feasibility. Allowing for effort to be set endogenously during turbulent times would not qualitatively alter the results. Note that because wages do not depend on turbulence, optimal effort would only change due to a higher probability of a layoff during turbulence.
} 
distribution for a higher value of $\sigma^{e}$. For example, a value of $\sigma^{e}=1$ induces a uniform distribution over skill levels smaller than or equal to the current one, whereas a value of $\sigma^{e}=0$ implies that current skills are fully retained. Our calibration below implies that $\sigma^{L}>\sigma^{H}$, that is, less-educated workers experience greater skill loss upon separation than do college-educated workers. Put differently, the skills of less-educated workers are more job-specific, and hence less-educated workers' investment in skills depends more on expected job tenure.

\subsection{Wage Setting, Separations, and Employment Protection}

In continuing matches, wage bargaining between worker and firm takes place every period. Wages are set via Nash bargaining, with a downward wage rigidity that prevents the wage from falling below the "prevailing wage" for the same type of worker-firm matches. In non-turbulent times, Nash bargaining takes place such that the worker retains a share $\alpha$ of the resulting surplus. We denote the resulting wage by $w_{p}^{e}(x, h, t)$, where $e \in\{L, H\}$ and $p \in\{A, N\}$. Worker and firm bargain only over the wage; the effort that the worker puts into accumulating skills cannot be contracted. The downward wage rigidity takes the form of a law that states that for given worker characteristics $x, h$, and $t$, firms cannot pay a wage lower than the prevailing wage for the corresponding matches under normal conditions, $w_{p}^{e}(x, h, t)$. This rigidity always binds if the match is subject to a turbulence shock.

Given wage rigidity, only the firm's surplus can turn negative when a turbulence shock hits. The firm will decide to dissolve the relationship and fire the worker when the continuation value falls below a firing cost that summarizes the level of employment protection in the economy. The firing cost is proportional to the prevailing wage and increasing in worker tenure $t$ :

$$
\Phi_{p}^{e}(x, h, t)=f(t) w_{p}^{e}(x, h, t)
$$

The coefficient $f(t)$ captures the strength of employment protection for workers with $t$ years of tenure. The revenue generated by the firing cost goes to the government and helps finance unemployment benefits. The firing cost is zero in the model economy calibrated to the United States, but a positive firing cost applies when we match the model to German data.

The wage setting process in the model features two sources of potential inefficiencies. First, Nash bargaining does not provide the efficient level of incentives for investing in 
skills, because the worker bears the effort cost of investing but captures only a fraction of the surplus generated. Second, the downward wage rigidity can lead to inefficient separations: when a turbulence shock hits, the firm may fire the worker even if continuing the relationship would be efficient. We do not model the frictions that give rise to these inefficiencies, but rather impose a specific wage-setting process. The on-the-job training literature has established that first-best contracts are difficult to achieve and that a variety of frictions can lead to inefficient investment. In our setting, an efficient contract would require a long-term commitment to a contingent contract by worker and firm and contractibility of the worker's effort. Hence, inefficiencies will arise if the worker's effort is unobservable or unverifiable, or if worker and firm cannot commit not to renegotiate a contract in the future. These frictions are likely to be relevant in our context: for example, workers are generally unable to commit not to quit a job, and can therefore use the threat of quitting to force a renegotiation.

We impose the downward wage rigidity because without such a friction, the model would generate large and counterfactual temporary wage reductions when a turbulence shock hits. The wage rigidity can be motivated with an information friction if the firm has private information about the turbulence shock. Arguably, firms are better informed about productivity than workers, and workers will not agree to labor contracts that allow the firm to reduce their wage arbitrarily based on information the worker cannot verify.

Our wage-setting assumptions are designed to be similar to benchmark labor search models while avoiding large wage cuts and providing incentives to invest in skills. However, the literature does not provide clear guidance about which wage setting process provides the best match to the data in our setting. We consequently have explored alternative wage setting mechanisms, such as Nash bargaining without a downward wage rigidity. The basic conclusions of our analysis with respect to the sources of change in the college wage premium are robust to alternative assumptions (provided that the model is re-calibrated to match the same data moments). In contrast, wage setting is relevant to welfare considerations when comparing different levels of employment protection. We return to this point below.

\subsection{The Decision Problems of Workers and Firms}

We now have all of the pieces in place to describe the decision problems faced by workers and firms in the model economy. First, consider a worker with education $e \in\{H, L\}$, experience $x$, skill $h$, and tenure $t$, who is currently employed in a type- $A$ job (accumula- 
tion of skills is possible). The only decision that this worker makes is how much effort $z$ to put into acquiring more skills. As long as the worker-firm match is not currently experiencing a turbulence shock, the decision problem for this worker is described by the following Bellman equation:

$$
\begin{array}{r}
V_{A}^{e}(x, h, t)=\max _{z}\left\{w_{A}^{e}(x, h, t)-a^{e}(x) h z^{2}+\beta\left[(1-\theta(t))(1-\gamma) E_{h^{\prime}}\left(V_{A}^{e}\left(x+1, h^{\prime}, t+1\right)\right)\right.\right. \\
\left.\left.+(1-\theta(t)) \gamma E_{h^{\prime}, \epsilon}\left(\tilde{V}_{A}^{e}\left(x+1, h^{\prime}, t+1, \epsilon\right)\right)+\theta(t) E_{h^{\prime}}\left(U^{e}\left(x+1, h^{\prime}\right)\right)\right]\right\} .
\end{array}
$$

Here, $U^{e}\left(x+1, h^{\prime}\right)$ is the value function in case of unemployment tomorrow and $\tilde{V}_{A}^{e}(x+$ $\left.1, h^{\prime}, t+1, \epsilon\right)$ is the value of being in an employment relationship tomorrow with turbulence shock $\epsilon$, which can be equal to the utility of unemployment if $\epsilon$ is sufficiently low to induce separation. If the relationship continues, the expectation over $h^{\prime}$ is governed by effort $z$ through the upgrade probability $p(z)$ defined in Equation (2). If the worker becomes unemployed, expectations over $h^{\prime}$ depend on the skill-loss probabilities defined by Equations (3) and (4). The expectation over the size of the turbulence shock $\epsilon$ is governed by the distribution function $G(\epsilon)$.

Workers with a job that does not allow for skill accumulation (who are always less educated) have no decisions to make, because quitting voluntarily is never optimal for workers. Their utilities are described by the Bellman equation:

$$
\begin{aligned}
& V_{N}^{L}(x, h, t)=w_{N}^{L}(x, h, t)+\beta\left[(1-\theta(t))(1-\gamma) V_{N}^{L}(x+1, h, t+1)\right. \\
& \left.+(1-\theta(t)) \gamma E_{\epsilon}\left(\tilde{V}_{N}^{e}(x+1, h, t+1, \epsilon)\right)+\theta(t) E_{h^{\prime}}\left(U^{e}\left(x+1, h^{\prime}\right)\right)\right] .
\end{aligned}
$$

If the worker-firm match is currently experiencing a turbulence shock, the firm will fire the worker if the shock $\epsilon$ is below a threshold $\tilde{\epsilon}_{p}^{e}(x, h, t)$, which is determined by the firm's problem. Hence, if $\epsilon<\tilde{\epsilon}_{p}^{e}(x, h, t)$, the continuation value for the worker is equal to the expected value of unemployment, where expectations are based on the probability distribution over skill losses, $Q^{e}(i, j)$, which is defined by Equations (3) and (4):

$$
\tilde{V}_{p}^{e}(x, h, t, \epsilon)=E_{h^{\prime}}\left[U^{e}\left(x, h^{\prime}\right)\right]
$$

Conversely, if $\epsilon \geq \tilde{\epsilon}_{p}^{e}(x, h, t)$ the value function for a worker with a type- $A$ job is:

$$
\tilde{V}_{A}^{e}(x, h, t, \epsilon)=w_{A}^{e}(x, h, t)-a^{e}(x) h z^{*}(x, h, t)^{2}
$$




$$
\begin{aligned}
& +\beta\left[(1-\theta(t))(1-\gamma)(1-\epsilon) E_{h^{\prime}}\left(\tilde{V}_{N}^{e}\left(x+1, h^{\prime}, t+1, \epsilon\right)\right)\right. \\
& \quad+(1-\theta(t))(1-\gamma) \epsilon E_{h^{\prime}}\left(V_{N}^{e}\left(x+1, h^{\prime}, t+1\right)\right) \\
& \left.\quad+(1-\theta(t)) \gamma E_{h^{\prime}, \epsilon^{\prime}}\left(\tilde{V}_{N}^{e}\left(x+1, h^{\prime}, t+1, \epsilon^{\prime}\right)\right)+\theta(t) E_{h^{\prime}}\left(U^{e}\left(x+1, h^{\prime}\right)\right)\right] .
\end{aligned}
$$

The value function reflects the possibility of productivity returning to the regular level (with probability $(1-\theta(t))(1-\gamma) \epsilon$ ) and the possibility of being hit by an additional turbulence shock (with probability $(1-\theta(t)) \gamma$ ). The value function under turbulence for type- $N$ jobs is analogous. The utility of unemployed workers is described by the Bellman equation:

$U^{e}(x, h)=(1-\lambda)\left[a^{e}(x) h b+\beta U^{e}(x+1, h)\right]+\lambda\left[\nu_{A}^{e} V_{A}^{e}(x+1, h, 1)+\left(1-\nu_{A}^{e}\right) V_{N}^{e}(x+1, h, 1)\right]$,

Here, $\nu_{A}^{e}$ is the equilibrium share of type- $A$ vacancies that allow for the accumulation of skills. For college-educated workers, we always have $\nu_{A}^{H}=1$, but for less-educated workers this share depends on the job-creation decisions of firms. Note that unemployed workers find a new job right away with probability $\lambda$. Given that our model is formulated at an annual frequency, requiring at least one period of unemployment after a layoff would imply a counterfactually long duration of unemployment. Unemployment compensation is given by a fraction $b<1$ of regular match productivity $a^{e}(x) h$.

We now turn to firms. The expected profit of a firm currently employing a worker with education $e$, experience $x$, skill $h$, and tenure $t$ in a type- $A$ job is given by:

$$
\begin{aligned}
J_{A}^{e}(x, h, t)=a^{e}(x) h-w_{A}^{e}(x, h, t)+\beta(1-\theta(t)) & \\
& {\left[(1-\gamma) E_{h^{\prime}}\left(J_{A}^{e}\left(x+1, h^{\prime}, t+1\right)\right)+\gamma E_{h^{\prime}, \epsilon}\left(\tilde{J}_{A}^{e}\left(x+1, h^{\prime}, t+1, \epsilon\right)\right)\right] . }
\end{aligned}
$$

The expected profit derived from a type- $N$ job is:

$$
\begin{aligned}
& J_{N}^{L}(x, h, t)=a^{L}(x) h-w_{N}^{L}(x, h, t)+\beta(1-\theta(t)) \\
& {\left[(1-\gamma) J_{N}^{L}(x+1, h, t+1)+\gamma E_{\epsilon}\left(\tilde{J}_{N}^{L}(x+1, h, t+1, \epsilon)\right)\right] . }
\end{aligned}
$$

These Bellman equations assume that the expected profit after a separation is zero. It is straightforward to generate the zero-profit condition for vacant firms in the standard way by adding a vacancy posting cost, a standard matching function, and a free entry condition for posting vacancies. This would add additional parameters (such as matching 
efficiency) that would then be chosen to generate the job-finding rate that we target in our calibration. As already mentioned, since we do not focus here on explaining how the job finding rate varies over time, we simplify this aspect of the model by imposing zero profits for vacant firms.

Next, consider the value of a matched firm currently experiencing a turbulence shock $\epsilon$. If the value of the firm conditional on continuation is below the education- and tenurespecific firing cost, separation occurs. Hence, the value of the firm with a type- $N$ job and a turbulence shock $\epsilon$ is:

$$
\begin{array}{r}
\tilde{J}_{N}^{e}(x, h, t, \epsilon)=\max \left\{a^{e}(x) h \epsilon-w_{N}^{e}(x, h, t)+\beta(1-\theta(t))\right. \\
{\left[(1-\gamma)(1-\epsilon) \tilde{J}_{N}^{e}(x+1, h, t+1, \epsilon)+(1-\gamma) \epsilon J_{N}^{e}(x+1, h, t+1)+\right.} \\
\left.\left.\gamma E_{\epsilon^{\prime}}\left(\tilde{J}_{N}^{e}\left(x+1, h, t+1, \epsilon^{\prime}\right)\right)\right],-\Phi_{N}^{e}(x, h, t)\right\},
\end{array}
$$

where $\Phi_{N}^{e}(x, h, t)$ is the firing cost. For a type- $A$ job we have:

$$
\begin{gathered}
\tilde{J}_{A}^{e}(x, h, t, \epsilon)=\max \left\{a^{e}(x) h \epsilon-w_{A}^{e}(x, h, t)+\beta(1-\theta(t))\right. \\
{\left[(1-\gamma)(1-\epsilon) E_{h^{\prime}}\left(\tilde{J}_{A}^{e}\left(x+1, h^{\prime}, t+1, \epsilon\right)\right)+\right.} \\
\left.\left.(1-\gamma) \epsilon E_{h^{\prime}}\left(J_{A}^{e}\left(x+1, h^{\prime}, t+1\right)\right)+\gamma E_{h^{\prime}, \epsilon^{\prime}}\left(\tilde{J}_{A}^{e}\left(x+1, h^{\prime}, t+1, \epsilon^{\prime}\right)\right)\right],-\Phi_{A}^{e}(x, h, t)\right\} .
\end{gathered}
$$

The optimal firing decision of the firm arising from these value functions defines the firing thresholds $\tilde{\epsilon}_{p}^{e}(x, h, t)$ below which the firm lets go of the worker.

After a worker retires, the value of the firm and the utility of the worker are both zero irrespective of skill level. As a result, the optimal choice of effort in the period preceding retirement is equal to zero. We also assume that the government finances unemployment benefits and spends revenue from the firing cost via lump-sum taxes and transfers that are identical for all workers. Given that utility is linear in consumption, these taxes and transfers do not affect any decisions. They therefore do not appear in the value functions, which should then be interpreted as utility net of the consumption derived from lump-sum transfers and taxes.

\section{Model Calibration: Matching US Data for 1980 and 2010}

In this section, we calibrate the model to match salient features of the US labor market in the 1980s and the 2010s. This calibrated model allows us to quantify the extent to which 
the rise of economic turbulence can account for changes in education wage premia. We then explore how labor protection legislation can help explain the different trends in the US and German economies following rising turbulence starting in the 1980s.

Our calibration procedure is comprised of three steps. First, we directly assign values to a subset of parameters that are common in the literature. The remaining parameters are divided into two sets, one that is time-invariant and one that is allowed to change over time (such as the frequency of turbulence shocks). In the second step, we calibrate both sets of parameters such that the steady state of the model matches a set of target moments for the US economy in 1980. In the third step, we recalibrate the time-variant parameters to match a set of target moments for the year 2010.

Step 1: Assigned parameters We set the model period to be one year. The discount factor is $\beta=0.95$, which implies a yearly interest rate of 5.3 percent. The worker's bargaining weight is set to $\alpha=0.5$, consistent with Gertler and Trigari (2009). The job finding rate is set to $\lambda=0.8$, implying an average job search duration of three months. The coefficient of the flow value of unemployment is set to $b=0.2$, which reproduces an average ratio of non-market to market production of 20 percent, consistent with an average replacement ratio of 40 percent for half of the currently unemployed labor force. The distribution $G(\epsilon)$ of turbulence shocks is given by a uniform distribution on the interval $[0, \bar{\epsilon}]$. We set the value of $\bar{\epsilon}$ to 0.6 , implying a minimum productivity loss of 40 percent of regular productivity during turbulent times. This choice can be interpreted as a normalization, since the model can rationalize the empirical share of workers with long-term tenure with multiple combinations of frequencies of turbulence shocks, $\gamma$, and minimum productivity losses, $\bar{\epsilon}$. In the case of a repeated turbulence shock, the new $\epsilon$ is once again uniformly distributed but on the interval $[0, \hat{\epsilon}]$, where $\hat{\epsilon}$ is the current turbulence shock. Table 3 summarizes the assigned parameters.

Step 2: Matching the 1980 US steady state Next, we jointly calibrate the remaining parameters to match a set of target moments that characterize the US economy in the early 1980s. The key moments of interest are the overall college wage premium, lifetime wage growth, and the returns to long-term tenure for college-educated and less-educated workers, as well as the share of workers with long-term tenure.

We impose two normalizations to help calibrate the model parameters. College-educated workers always invest in skills, which makes it difficult to identify how much of their 


\begin{tabular}{clcl}
\hline Parameter & Interpretation & Value & Source/Target \\
\hline$\beta$ & Discount rate & 0.95 & Yearly interest rate 5.25\% \\
$\lambda$ & Job finding rate & 0.8 & Av. duration unemployment 3 months \\
$\alpha$ & Bargaining weight & 0.5 & Gertler and Trigari (2009) \\
$b$ & Non-market productivity & 0.2 & Half receive replacement rate $40 \%$ \\
$\bar{\epsilon}$ & Prod. loss in turbulence & 0.6 & Minimum 40\% loss \\
\hline
\end{tabular}

Table 3: Directly assigned model parameters

wage growth is due to endogenous investment versus their exogenous lifetime experience profile. In this analysis, we impose that the exogenous productivity term for collegeeducated workers, $a^{H}(x)$, is constant in experience, meaning that the lifetime wage growth of college graduates is entirely accounted for by the endogenous accumulation of skills on the job. The constant productivity level for college-educated workers in the 1980s calibration is denoted by $A_{80}^{H}$. Given the parameters that control the accumulation and loss of skills, we can then calibrate the productivity process for less-educated workers, $a^{L}(x)$, to match the profile of the college premium across different age groups. We impose that the exogenous productivity term grows with experience at a constant rate, denoted by $g_{80}^{L}$ :

$$
a_{80}^{L}(x)=A_{80}^{L}\left(1+g_{80}^{L}\right)^{x-1},
$$

where we choose units so that $A_{80}^{L}=1$. A second normalization concerns the share of type- $A$ jobs for less-educated workers that allow investment in skills. Since returns to experience can be explained by different combinations of fractions of type- $A$ jobs and exogenous returns to experience, we impose that in 1980 all the vacancies for $L$ workers are of type $A$, i.e. $\nu_{A, 80}^{L}=1$ (meaning that the parameter $c_{1}$ defining the upper bound for the cost of creating a type- $A$ job is sufficiently low). What matters for our quantitative findings is the change in the share of type- $A$ jobs over time rather than the initial level of such jobs.

The remaining parameters are jointly calibrated to match a set of target moments derived from the PSID for the years 1981-1986. ${ }^{12}$ Though the parameters do interact, there is a specific target moment for most parameters that plays an outsized role in setting the parameter value.

\footnotetext{
${ }^{12}$ We use multiple years for the calibration to reduce measurement error due to small sample sizes.
} 


\begin{tabular}{clcl}
\hline Parameter & Interpretation & Value & Related Targets \\
\hline$\sigma^{L}$ & $L$ skill specificity & 0.318 & $L$ tenure premium \\
$\sigma^{H}$ & $H$ skill specificity & 0.045 & $H$ tenure premium \\
$\psi$ & Prob. skill upgrade & 0.494 & Experience and college premia \\
$g_{80}^{L}$ & $L$ productivity growth & 0.0006 & Experience and college premia \\
$A_{80}^{H}$ & Skill bias & 1.290 & College wage premium \\
$\gamma_{80}$ & Prob. turbulence shock & 0.013 & Long-term tenure \\
$\theta_{80}(1)$ & Prob. separation shock & 0.207 & Short-term tenure \\
$\eta$ & Pareto initial skills & 4.571 & $L$ std. dev. log wage at age 25 \\
\hline
\end{tabular}

Table 4: Calibrated parameter values for 1980 steady state

The jointly calibrated parameters are summarized in Table 4 . The distribution of skills for workers entering the labor market, $F(h)$, is assumed to be a Pareto with shape parameter $\eta$. The value for $\eta$ is set to match the standard deviation of $\log$ hourly wages for high-school graduates at age 25 , which is given by 0.364 .

The parameters that control the loss of skills upon separation, $\sigma^{L}$ and $\sigma^{H}$, are set to match the wage premium enjoyed by long-tenure workers. Specifically, we target the wage premium of workers aged $45-54$ with job tenures of between 20 and 30 years over workers in the same age range with tenures of between 0 and 10 years. The calibrated values imply a substantial loss of skills for workers of type $L$ ( $\sigma^{L}$ is calibrated to be 0.318 ), while the loss of skills for workers of type $H$ is considerably smaller $\left(\sigma^{H}\right.$ is calibrated to be 0.045$)$. These calibrated values imply that less-educated workers acquire skills that are more job-specific compared to college graduates. Figure 10 in Appendix $\mathrm{C}$ displays the distribution functions over skill levels $h_{i}$ after job loss. A less-educated worker with current skill $h=h_{10}$ (i.e., the 10th step of the ladder) loses an average of 6.4 percent of their skills upon separation, compared to only 0.7 percent for a college-educated worker. The parameters controlling the accumulation of skills on the job, $\psi$, and the exogenous productivity growth with age for $L$-workers, $g_{80}^{L}$, are calibrated to target college wage premia for the age groups $25-34,35-44$, and $45-54$, and the experience premia of $\mathrm{H}$ workers aged $35-44$ and $45-54$ compared to workers aged $25-34$. This procedure targets the difference in the steepness of the age-earning profile between college-educated and less-educated workers and, hence, the increase in the college premium over the life cycle. 


\begin{tabular}{lcc}
\hline Moment & Data & Model \\
\hline$L$ tenure premium & 0.238 & 0.232 \\
$H$ tenure premium & 0.126 & 0.127 \\
Long tenure share & 0.414 & 0.414 \\
Short tenure share & 0.154 & 0.155 \\
$L$ standard deviation log wage at 25 & 0.364 & 0.367 \\
College premium 25-34 & 0.244 & 0.234 \\
College premium 35-44 & 0.282 & 0.302 \\
College premium 45-54 & 0.367 & 0.357 \\
$H$ experience premium 35-44 & 0.229 & 0.209 \\
$H$ experience premium 45-54 & 0.383 & 0.395 \\
\hline
\end{tabular}

Table 5: Model fit for 1980 calibration

The parameters controlling the frequency of turbulence shocks and exogenous separations are determined by the share of workers with short-term and long-term tenure with their current employer. Specifically, the probability of a turbulence shock, $\gamma_{80}$, is set to match the share of workers of ages 45-54 with current job tenure between 20 and 30 years, which is 41.4 percent in our calibration period. As for exogenous separations, we impose a process that declines to zero at a constant rate over the first 10 years of a job relationship. This process is parameterized by the exogenous separation probability in the first year $\theta_{80}(1)$. We pick the value of $\theta_{80}(1)$ to match the share of short-tenure jobs (less than two years of tenure) among workers aged 35-44, which is 15.4 percent in the target period. Introducing this additional source of separations will allow us to account for the simultaneous decline in jobs with long-term tenure and the stable fraction of jobs with short tenure. The calibrated process for exogenous separations as a function of tenure in the 1980 calibration is depicted by the solid line of Figure 11 in Appendix C

The calibrated parameters for the 1980 US steady state are listed in Table 4, and Table 5 compares the fit for the target moments between model and data. The calibrated model successfully replicates the education and experience premia, tenure premia, and the tenure distribution observed in the data. Further details on the calibration procedure are provided in Appendix B. 
Step 3: Matching the 2010 Steady State Finally, we recalibrate the model to match a set of target moments from the early 2010s. Our primary objective is to determine the sources of the increase in the college wage premium from the 1980s to the 2010s. The calibration procedure allows for multiple sources of changing wage premia, including changes in turbulence and changes in the overall skill bias of technology. The calibration procedure helps to identify these different channels by matching observed changes in returns to experience, returns to college, and the tenure distribution.

For the 2010 calibration, we stipulate that the parameters $\eta, \psi, \sigma^{H}$, and $\sigma^{L}$ are unchanged from the 1980s. The remaining parameters are chosen such that the resulting steady state of the model matches a set of target moments from the PSID for the years 2009-2013. In the calibration, we treat the share of type- $A$ jobs, $\nu_{A, 10}^{L}$, as a parameter. We later back out the values of the structural parameters $c_{0}$ and $c_{1}$, which generate the calibrated shares $\nu_{A, 80}^{L}$ and $\nu_{A, 10}^{L}$ following Equation (1), and use these parameters to generate counterfactuals and decompositions.

We allow for two sources of change in the wage structure that are unrelated to the turbulence mechanism. First, we allow for an overall change in returns to experience, $g_{10}^{e}$, which applies equally to college-educated and less-educated workers. This shift is denoted by $\Delta g_{10}$, and serves to capture changes in the age-wage profile that are not due to investment in skills on the job. Second, we allow for a shift in the overall skill bias $A_{10}^{H}$, i.e., the overall productivity of college-educated versus less-educated workers, which captures factors such as skill-biased technical change. Including these elements allows us to match the change in the college wage premium exactly and then decompose it into contributions from different channels.

The skill bias parameter $A_{10}^{H}$, the change in returns to experience $\Delta g_{10}$, and the job composition parameter $\nu_{A, 10}^{L}$ are calibrated by matching the college wage premia for age groups $25-34,35-44$, and $45-54$, as well as the experience premia of $H$-workers aged 35-44 and 45-54 (again compared to workers aged 25-34). The calibration implies an increase in overall returns to experience $\left(\Delta g_{10}>0\right)$ and a substantial decline in the share of type- $A$ jobs that allow for the accumulation of skills. These findings reflect an increase in the steepness of the age-earnings profile for college-educated workers and a rise in the college wage premium among older workers.

To estimate the frequency of the turbulence shocks, $\gamma_{10}$, we target the change in the share of workers aged 45-54 with current tenures of between 20 and 30 years from the $1980 \mathrm{~s}$ to the 2010s. This share declines by 8.07 percentage points, implying a 2.40 


\begin{tabular}{clcl}
\hline Parameter & Interpretation & Value & Related Targets \\
\hline$\Delta g_{10}$ & Change product. growth & 0.006 & Experience and college premia \\
$\nu_{A, 10}^{L}$ & Share of type- $A$ jobs & 0.555 & Experience and college premia \\
$A_{10}^{H}$ & Skill bias & 1.499 & Experience and college premia \\
$\gamma_{10}$ & Prob. turbulence shock & 0.037 & Long-term tenure \\
$\theta_{10}(1)$ & Prob. separation shock & 0.173 & Short-term tenure \\
\hline
\end{tabular}

Table 6: Calibrated parameter values for 2010 steady state

\begin{tabular}{lcc}
\hline Moment & Data & Model \\
\hline Change long tenure share & -0.081 & -0.081 \\
Change short tenure share & 0.009 & 0.009 \\
$H$ experience premium, 35-44 & 0.307 & 0.275 \\
$H$ experience premium, 45-54 & 0.506 & 0.522 \\
College premium 25-34 & 0.408 & 0.411 \\
College premium 35-44 & 0.541 & 0.537 \\
College premium 45-54 & 0.645 & 0.647 \\
\hline
\end{tabular}

Table 7: Model fit for 2010 steady state

percentage point increase of the estimated value for $\gamma$. Similarly, to pin down the frequency of exogenous separations for short-duration jobs, $\theta_{10}(t)$, we target the change in the share of workers aged 35-44 with current tenure below two years from the 1980s to the 2010s. The calibrated value of $\theta(1)$ declines by 3.43 percentage points, consistent with observations in the literature (e.g., Hyatt and Spletzer 2016, Molloy, Smith, and Wozniak 2019) documenting a recent decline in the prevalence of short-duration jobs. Figure 11 in Appendix $C$ illustrates how the estimated process for exogenous separations has changed between the 1980 and 2010 calibrations.

Parameter values and the fit for targeted moments for the 2010 calibration are summarized in Tables 6 and 7. The model successfully reproduces the observed changes in the tenure distribution, returns to experience, and the college wage premium at different ages. 


\section{Findings from the Quantitative Model}

We now examine the extent to which the model can account for variation in the college wage premium over time and across countries. First, we examine the sources of the increase in the college wage premium in the United States, and then ask whether strict employment protection can account for the relatively stable college wage premium in Germany.

\subsection{The Rise in the College Wage Premium in the United States}

The two model calibrations for the United States in the 1980s and 2010s fully account for the increase in the college wage premium during this period. In this section, we examine the relative importance of the turbulence mechanism in accounting for this change.

Figure 4 provides a snapshot of the mechanism through which labor market turbulence affects the college wage premium in the model. The figure displays the probability that a worker with one year of tenure and at the bottom of the skill ladder $\left(t=1, h=h_{1}\right)$ will move up to the next step of the ladder, based on age and education..$^{13}$ The probability of upgrading skills declines for older workers, which reflects the shorter investment horizon for workers who are closer to retirement.

In the 1980 calibration, the probability of accumulating skills is only slightly higher for college-educated workers (solid line) than for less-educated workers (dashed line), mainly because these workers' skills are more transferable. In contrast, less-educated workers are much less likely to upgrade their skills in the 2010 calibration. This is due to the higher level of turbulence shocks: workers and firms are both aware that matches are less likely to be long-lived, which reduces the incentive to make match-specific investments. For college-educated workers, investment in skills does not decrease. Because these workers primarily accumulate transferable skills, their investment depends less on the level of turbulence and, therefore, on the longevity of matches. In fact, the likelihood that they upgrade their skills increases slightly due to the steeper productivity profile implied by $\Delta g_{10}$, which induces higher incentives to exert effort in skill accumulation. The same effect applies to less-educated workers, though to a lesser extent due to these workers' high degree of skill specificity.

The decline in skill upgrading for less-educated workers from 1980 to 2010 reflects lower investment from both sides: firms create fewer vacancies that allow for the accumulation

\footnotetext{
${ }^{13}$ The trends are qualitatively identical for workers with higher tenure and skill levels.
} 


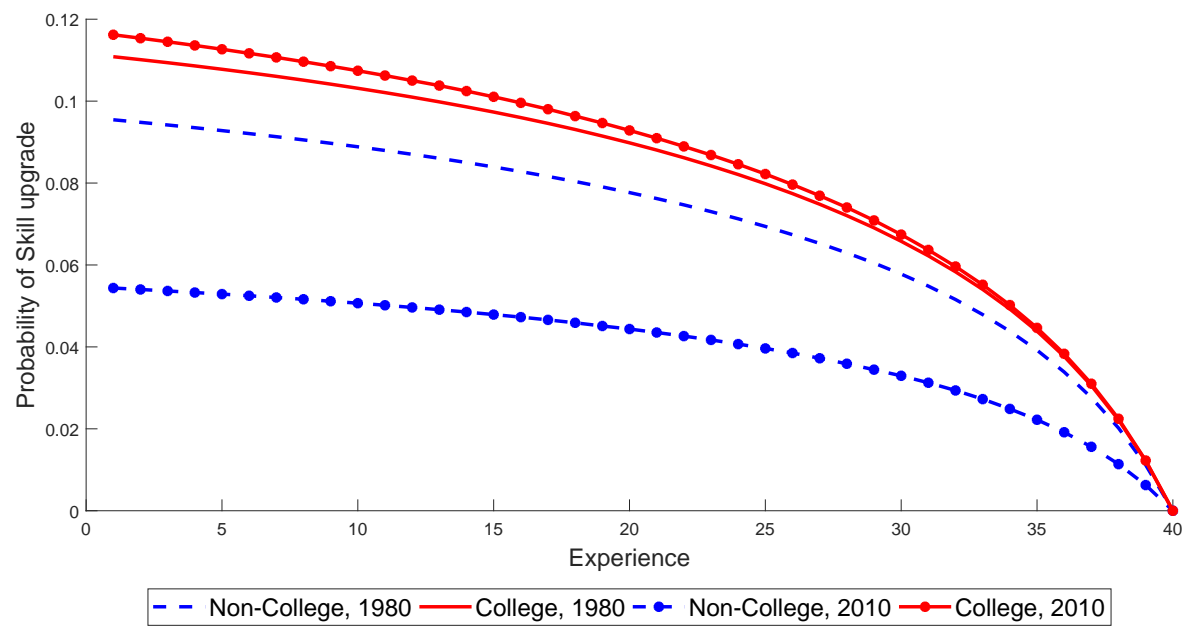

Figure 4: Probability of skill upgrading by years of experience for $L$ (dotted lines) and $H$ (solid lines) workers with tenure $t=1$ and skill $h=h_{1}$, US calibration for 1980 (plain lines) and 2010 (marked lines).

of skills, while workers in jobs that do allow for skill accumulation invest less in onthe-job skill acquisition. In the calibrated model, the firm investment channel is more important: the lower availability of accumulation-type jobs accounts for over 90 percent of the wider gap in skill upgrading among workers with no experience $(x=1)$ and minimum skills $\left(h=h_{1}\right)$.

The decline in the investment in relationship-specific capital among less-educated workers results in a decline in their average human capital, and hence in a rise in the measured college wage premium. The solid lines of Figure 5 show that the end-of-career (age 64) skill distribution of college graduates stays roughly the same between the two steady states. For these workers, the skill loss due to higher turbulence is moderate and fully compensated by an increase in on-the-job investment in skills. By contrast, the distribution of skills for less-educated workers (dashed lines) is shifted lower. A large part of this shift is due to the endogenous adjustment of job creation towards more type- $N$ jobs that do not allow accumulation of skills. However, even when the job composition is held constant at the 1980 values (diamond markers), the increase in turbulence and the resulting surge in separations result in a substantial decline in accumulated human capital.

Table 8 breaks down how these changes affect the college wage premium in the model economy. The first two rows show the college premia in the 1980 and 2010 calibrations, 


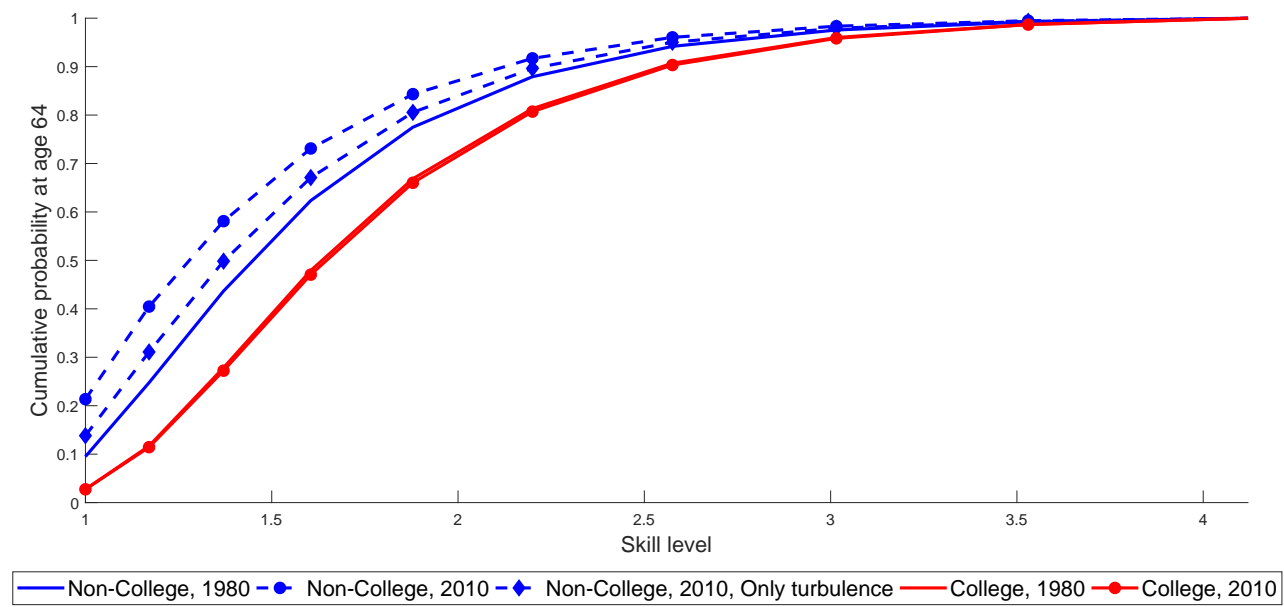

Figure 5: Distribution of the skills of less-educated (dashed lines) and college-educated (solid lines) workers at age 64, US calibration for 1980 (plain lines) and 2010 (marked lines). The line with diamond markers denote the case in which only turbulence shocks and individual effort are changed to the 2010 values, while the composition of vacancies is kept to the 1980 value.

which closely match the data since college wage premia by age were included as target moments. The overall college premium increases by 43 percentage points, more than doubling between the two steady states. This is partially due to the mechanism of onthe-job investment in skills and partially to the rise in the overall skill bias parameter. In order to separate those channels, the third row of Table 8 shows the college premium that the model generates in 2010 if we only feed in the consequences of larger turbulence shocks. For this counterfactual, we focus entirely on the turbulence channel by leaving wages and other parameters (including overall skill bias) unchanged at the 1980 level, but changing the frequency of turbulence shocks and imposing the policy functions that affect investment in skills by firms and workers to reflect their values in the 2010 calibration. We see that this mechanism alone leads to a 16-percentage point rise in the college wage premium or 37 percent of the overall increase. Hence, in the quantitative model, the mechanism of skill accumulation accounts for a substantial fraction of the rise in the college premium. The remainder of this increase is primarily due to the rise in the skill bias parameter $A_{H}$, which captures channels already documented by the literature, such as skill-biased technical change.

Higher turbulence shocks increase the college premium in part because firms create fewer jobs that allow for the accumulation of skills, and in part because workers who do have 


\begin{tabular}{lc}
\hline Setting & College Premium \\
\hline 1980 calibration & 0.38 \\
2010 calibration: turbulence and skill-biased technical change & 0.81 \\
2010 calibration: only turbulence (changing job composition) & 0.54 \\
2010 calibration: only turbulence (fixed job composition) & 0.40 \\
\hline
\end{tabular}

Table 8: The college wage premium in the model, 1980 and 2010 calibrations, full model versus models with only the turbulence mechanism

such jobs have fewer incentives to accumulate skills and are fired more frequently. The last row of Table 8 shows the change in the college premium if we also fix the composition of job types, and hence isolate the effect of worker investment in skills. The increase in the college premium is still positive but much smaller in magnitude (two percentage points, as compared to 16 percentage points due to turbulence). Hence, the shift towards jobs that do not allow for accumulation of skills accounts for most of the effect of turbulence on the college premium.

The shift towards lower-quality jobs that do not allow for the accumulation of skills is driven by a change in the relative profitability of the two types of vacancies. Figure 6 displays the gap in the relative expected profitability between jobs that allow for skill accumulation versus those that do not as a function of the initial skill level of the worker that is hired. Accumulation-type jobs are in general more profitable, especially when matched with workers from the left of the skill distribution, who have high potential for skill accumulation. However, the increase in turbulence reduces the profitability advantage of accumulation-type jobs, primarily because of the higher likelihood of shocks that will lead to separation. Given that these jobs are more costly to create, this shift in profitability has a considerable effect on equilibrium job composition.

\subsection{The College Wage Premium Across Cohorts During the Transition}

So far, we have focused on a comparison of the college wage premium across the steady states of our model, which correspond to the 1980 and 2010 calibrations. However, given its life-cycle structure, the model also generates rich transitional dynamics. While we do not take a stand on the exact timing of the change in economic turbulence, a robust implication of the theory is that there are pronounced cohort effects during the transition. When economic turbulence rises, the workers who are initially most affected are young 


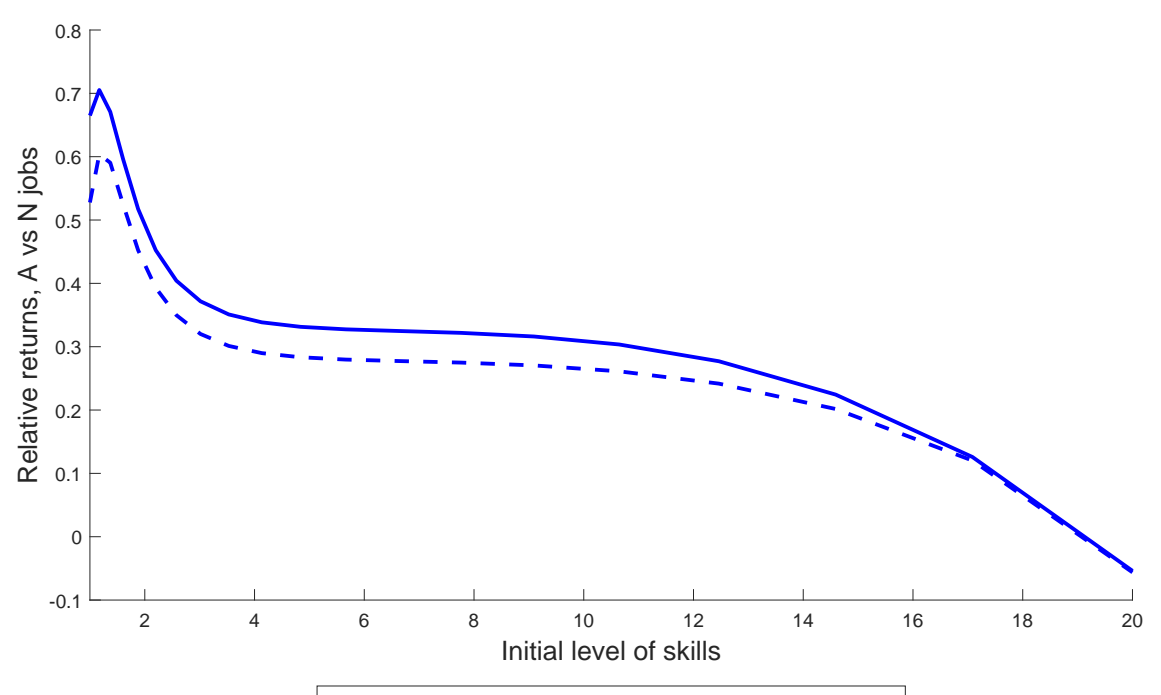

Non-College, 1980 - - Non-College, 2010

Figure 6: Profitability gap between jobs that do and do not allow for skill accumulation (type- $A$ versus type- $N$ vacancies) in the 1980 (solid line) and 2010 (dashed line) calibrations.

workers who have just entered the labor market. These workers have not yet accumulated any relationship-specific skills, and the composition of jobs available to them (in terms of the possibility of accumulating skills) will immediately reflect the change in turbulence. In contrast, older workers continue to benefit from skills they have already accumulated, as well as from the fact that many of them have jobs created in the past that allow for the accumulation of skills.

To illustrate the transitional dynamics of the model, we start the economy in the steady state corresponding to the 1980 calibration. Then, in 1981, the degree of turbulence $\gamma$ and the job composition for vacancies of $L$ workers changes unexpectedly and permanently to their values in the 2010 calibration. We then compute the transition path of the economy as subsequent cohorts enter the labor market.

Figure 7 shows how the college wage premium evolves differentially for younger and older workers during the transition. The graphs display the college premium relative to 1980 separately for younger (25 to 39) and older (40 to 54) workers. Since we impose a one-time change in the economic environment, all transitional dynamics are due to the endogenous progression of state variables. The figure shows that the college premium among younger workers rises substantially by 1990, whereas there is little change for the 

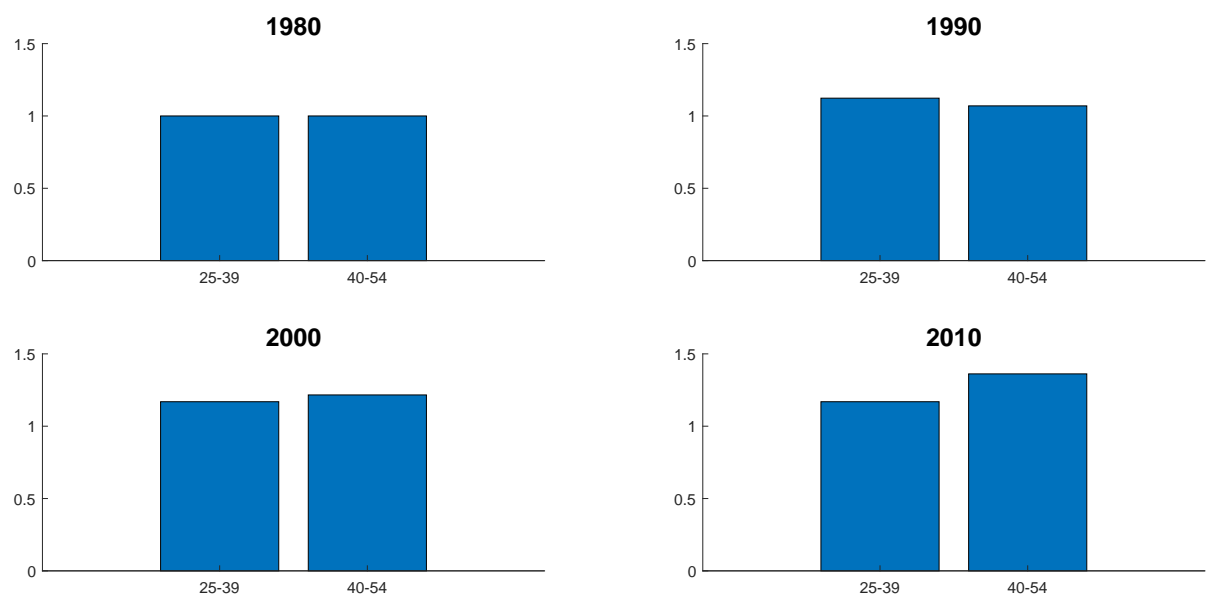

Figure 7: The college premium by age over time after a one-time increase in turbulence (model)

older workers. This reflects the fact that a substantial fraction of older workers in 1990 are still in jobs that were created before the shock took place in 1981. The next panels show that by 2000, the impact on younger and older workers is more even, with older workers more affected than younger ones by 2010. The larger effect on older workers in 2010 reflects the importance that the model places on the life-cycle accumulation of skills, meaning that the long-run impact on wages is larger for older workers at the end of their life cycles than for younger workers.

Figure 8 presents the same information using the data. The changes in the college premium are quantitatively larger because the dynamic model simulation only focuses on the turbulence channel. Qualitatively, however, the pattern in the data is exactly the same as in the model: in the first decade, the college premium rises primarily for the young, in the second decade the impact evens out, and in the long run it is the older workers who are more affected. ${ }^{14}$ This empirical pattern is suggestive of a mechanism that affects successive cohorts when they first enter the labor market. Our model of on-the-job investment in skills provides such a mechanism. It is encouraging that the key prediction of cohort effects in the rising college wage premium is supported by the data.

\footnotetext{
${ }^{14}$ The fact that the rise in the skill premium initially affected younger workers was first pointed out by Card and Lemieux (2001).
} 

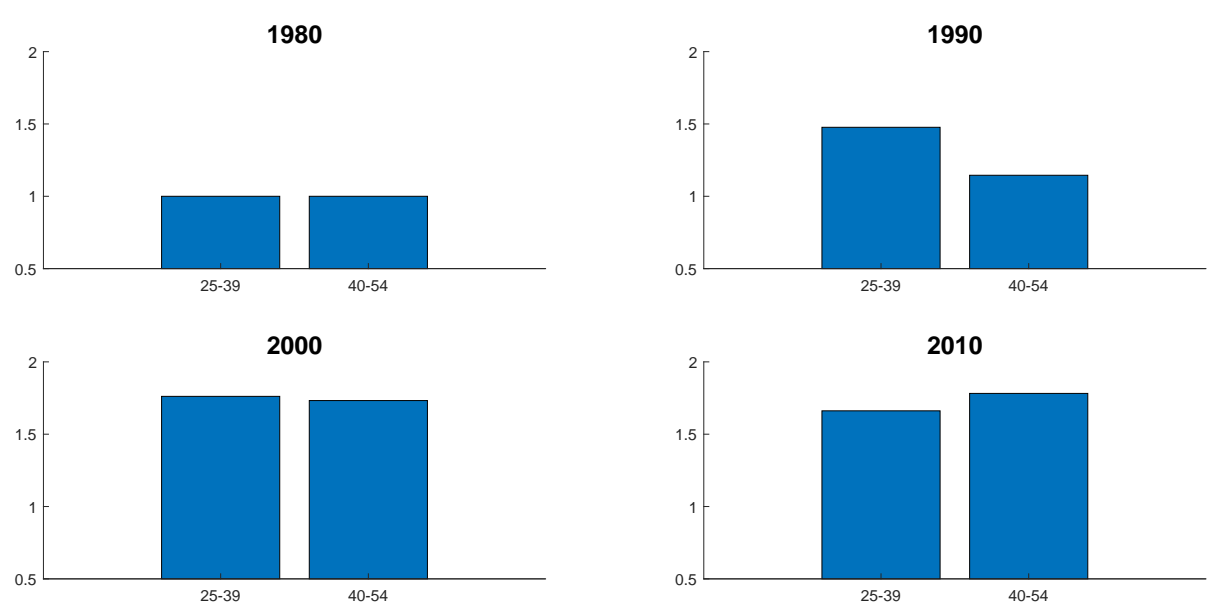

Figure 8: The college premium by age over time (US data)

\subsection{Labor Protection and the College Wage Premium in Germany}

We now examine the extent to which labor protection legislation can help explain the much lower rise in the college premium in Germany compared to the United States from 1980 to 2010. We view the US and German economies as sharing the same overall technological environment, and hence both economies are subject to skill-biased technological change and increased turbulence. However, we propose that the impact of these changes was mitigated in Germany due to stronger employment protection.

To isolate the role of employment protection, we compute the college wage premium in the "Germany" variants of our 1980 and 2010 calibrations. These are identical to the US calibrations except for the firing cost that firms have to pay when laying off workers (which is zero in the US calibration). Given that there was little change in employment protection for regular workers in Germany over this period, we impose the same firing cost in 1980 and in 2010. ${ }^{15}$

Recall from Section 4.4 that the firing cost takes the following form:

$$
\Phi_{p}^{e}(x, h, t)=f(t) w_{p}^{e}(x, h, t)
$$

To capture the fact that workers with higher tenure enjoy more employment protection, we stipulate that the term $f(t)$ increases linearly with tenure over the first ten years of a

\footnotetext{
${ }^{15}$ The "Hartz" labor market reforms of the Schroeder government in the early 2000s reduced protection for temporary contracts but left protections for high-tenure regular-contract workers intact.
} 


\begin{tabular}{lcc}
\hline \multirow{2}{*}{ Setting } & \multicolumn{2}{c}{ College Premium } \\
\cline { 2 - 3 } & $\begin{array}{c}\text { No Firing Cost } \\
\text { "Firing Cost }\end{array}$ \\
\hline 1980 calibration & 0.38 & 0.38 \\
2010 calibration: turbulence and skill-biased tech. change & 0.81 & 0.60 \\
2010 calibration: only turbulence & 0.54 & 0.39 \\
\hline
\end{tabular}

Table 9: The rise in the college wage premium with and without employment protection

worker-firm match, and is constant afterwards. Hence, the firing cost is solely defined by the initial value of $f(1)$. Actual German employment protection laws do not take the form of an explicit firing cost, but rather consist of detailed rules on conditions under which a layoff is permissible, which include protections for older and higher-tenure workers. We pin down the extent of the firing cost for the "Germany" calibration by focusing on the effects of employment protection. Specifically, we target the difference in the share of workers aged 45-54 with current tenure of 20 to 30 years in Germany between the two steady states. ${ }^{16}$ This procedure results in $f^{D E}(1)=0.23$, implying that the firing cost is equal to 23 percent of the regular wage in the first year of a worker-firm relationship. This firing cost coefficient increases linearly to 230 percent of the regular wage once the worker reaches ten years of tenure. The left panel of Figure 12 in Appendix $C$ shows how $f^{D E}(1)$ is identified by the share of long-tenure workers, while the right panel depicts the magnitude of the estimated firing cost as a function of tenure.

Table 9 shows how labor protection affects the change in the college wage premium over time in the model economy. The left column reproduces the findings from Table 8 for the model without employment protection ("United States"). The right column shows the effect of labor protection on the college wage premium in the "Germany" calibrations with labor protection for 1980 and 2010. The effect of labor protection on the 1980 steady state is almost nil. This reflects the fact that low labor market turbulence reduces the importance of the firing cost. In the 2010 calibration (second row), the college wage premium in the "Germany" model increases by 22 percentage points, far less than the 43-percentage point increase observed in the "United States" model. Employment protection therefore reduces the increase in the skill premium by close to 50 percent and

\footnotetext{
${ }^{16}$ Analogously to the calibration for the United States, we use the years 2009-2013 for computing targets for the 2010s steady state. For the initial state, we use the first six years of data in GSOEP, 1984-1989.
} 


\begin{tabular}{lcc}
\hline & 1980 & 2010 \\
\hline "United States" & 1.645 & 1.539 \\
“Germany" & 1.720 & 1.843 \\
\hline
\end{tabular}

Table 10: Relative profitability of type- $A$ compared to type- $N$ vacancies across the two steady states in the "United States" economy (no firing cost) and in the "Germany" economy (with firing cost)

can account for much of the divergent trends in the college wage premium between the United States and Germany displayed in Figure 1. The last row of the table shows the impact of employment protection in the model with turbulence shocks but without additional skill-biased technological change. Here we see that employment protection prevents almost the entire 16-percentage point rise in the college wage premium that occurs without protection. Hence, while employment protection does not offset general skill-biased technological change, it does insulate the economy from the bulk of the effects of increasing turbulence.

Table 10 illustrates the economics behind these findings. The top row displays the relative profitability of type- $A$ over type- $N$ vacancies in the US calibration across the two steady states. The increase in turbulence induces a decline in the relative profitability of type- $A$ vacancies, prompting a shift towards type- $N$ vacancies and depressing the accumulation of skills for less-educated workers, which leads to an increase in the college wage premium. By contrast, in the "Germany" model with employment protection (bottom row), the relative profitability of type- $A$ vacancies actually increases after the rise in turbulence. Employment protection induces firms to retain workers even when relatively large turbulence shocks hit, regardless of the type of job. When the frequency of turbulence shocks increases, the profitability of type- $N$ jobs sees a greater reduction because the lower value of a type- $N$ match makes retaining a worker in times of turbulence relatively more costly. As a result, the fraction of type- $A$ vacancies does not decline as turbulence increases and, in equilibrium, the probability of a skills upgrade increases slightly (Figure 9).

\subsection{The Impact of Labor Protection on Welfare}

Table 11 describes how imposing employment protection affects output and welfare (on consumption units) in the economy. Compared to the 1980 benchmark, turbulence shocks on their own lower output and welfare because they lead to more frequent separations 


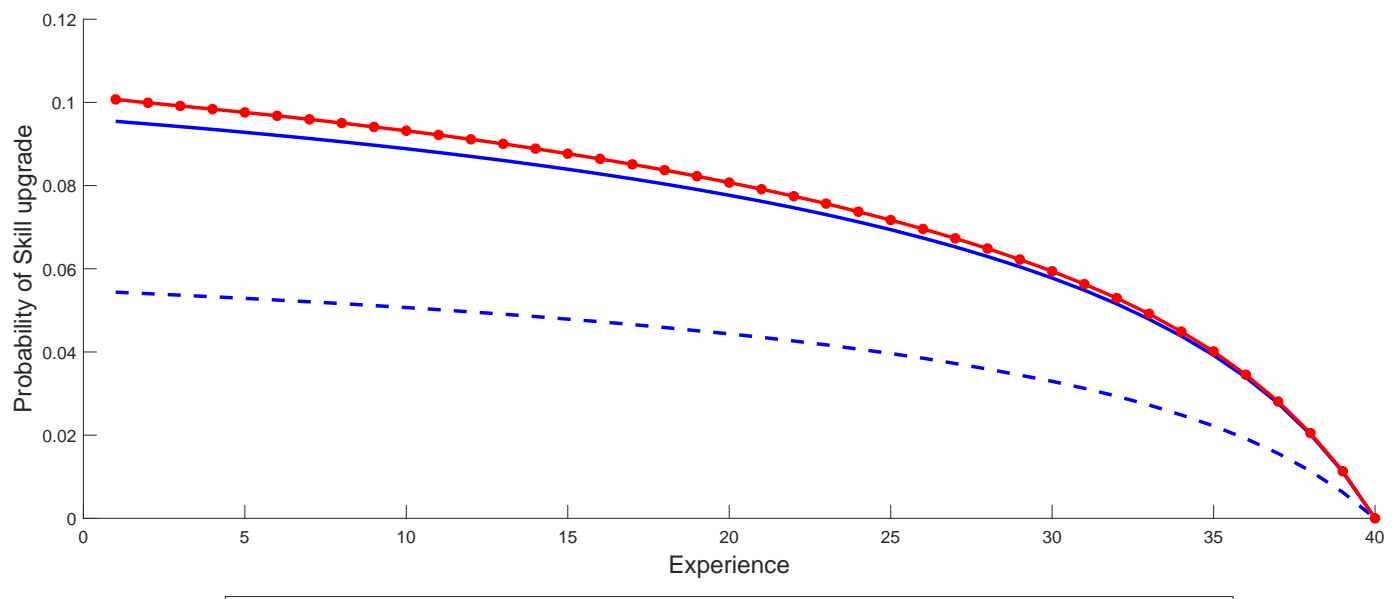

Non-College, US, 1980 - - Non-College, US, $2010 \longrightarrow$-Non-College, Germany, 2010

Figure 9: Probability of skill upgrading by years of experience for $L$ workers with tenure $t=1$ and skill $h=h_{1}$, "United States" calibration for 1980 (plain line) and 2010 (dotted line) and "Germany" calibration for 2010 (marked line).

and hence a greater destruction of job-specific capital. Employment protection lowers these losses both in terms of output and welfare. This result is due to a portion of separations in our model that occur in response to turbulence shocks being inefficient. Excessive separations generate an expectation of a short work relationship and hence dampen workers' and firms' incentives to invest in job-specific skills. Employment protection can prevent some of these separations, limit the destruction of skills, and produce incentives for greater accumulation of job-specific skills. However, the welfare effects of employment protection are not unambiguous: some inefficient separations may be prevented, but it may also preserve matches that should be terminated for reasons of efficiency.

In order to explore the sources of welfare gains brought about by employment protection, we decompose the welfare gains into two components. The last two rows of Table 11 show the results of this decomposition. First, we display the gains when the firing cost is constrained to only affect separations, while leaving workers' and firms' investment in skills unaffected. Restricting separations reduces both welfare and output compared to the unconstrained case. Given firing costs at the level of the German economy, the negative distortion from preventing separations counteracts the effect of the reduction in skill loss upon separation, since limiting separations eventually implies that matches that should be destroyed are inefficiently kept intact. The last row shows that the welfare 


\begin{tabular}{lcc}
\hline Setting & Output & Welfare \\
\hline 1980 & 1 & 1 \\
2010: turbulence & 0.925 & 0.931 \\
2010: turbulence, employment protection & 0.972 & 0.969 \\
2010: turbulence, employment protection (only separations) & 0.913 & 0.919 \\
2010: turbulence, employment protection (only investment) & 0.983 & 0.980 \\
\hline
\end{tabular}

Table 11: Output and welfare relative to 1980 in the model with turbulence and with employment protection

gains from introducing labor protection originate entirely from the increased incentives to invest in job-specific capital.

It is important to keep in mind that our model only provides for a partial welfare analysis and does not capture all tradeoffs that are relevant to the introduction of employment protection measures. First, welfare results are sensitive to assumptions on wage bargaining, in particular the downward wage rigidity. The extent to which wage bargaining fails to set efficient incentives for investing in relationship-specific skills is difficult to quantify. Second, our analysis keeps the job finding probability fixed. In a model with endogenous job creation, firing restrictions would affect labor market tightness and unemployment. ${ }^{17}$ For these reasons, this analysis should be interpreted as identifying a channel through which employment protection may have beneficial effects, which in a full analysis would have to be weighed against other well-known channels through which excessive protection may reduce welfare.

\section{Conclusion}

There are major differences in employment protection across countries. In Europe, widespread firing restrictions and insider-outsider labor markets protect senior workers at the expense of their junior and temporary counterparts. Excessive employment protection can lead to well-known negative repercussions, including the high levels of youth unemployment observed in a number of European countries.

In this paper, we consider a different channel through which certain forms of employment

\footnotetext{
${ }^{17}$ Bratti, Conti, and Sulis (2018) argue that excessive employment protection can also push more workers into temporary contracts and thereby reduce training.
} 
protection can have potentially beneficial effects. By creating the expectation of longlasting employment relationships, employment protection can facilitate investments by workers and firms in relationship-specific capital. Employment protection is especially valuable when frequent turbulence shocks threaten to generate inefficient separations and the destruction of such capital.

We argue that the impact of employment protection on relationship-specific investments can help explain divergent trends in the college wage premium between countries with tight employment protection such as Germany and countries with low levels of protection such as the United States. When turbulence shocks that temporarily lower the productivity of worker-firm matches become more frequent, the expected duration of employment relationships will fall in countries with little employment protection, resulting in less investment in relationship-specific capital. These effects are more pronounced for less-educated workers, whose skills are more job-specific than those of more educated workers. For this reason, a rise in turbulence raises the college wage premium in countries such as the United States, but has little impact in countries with greater employment protection such as Germany. We argue that the employment-protection mechanism can account for close to half of the divergent trends in the college wage premium between the United States and Germany. The mechanism is also consistent with observed trends in job tenure and returns to tenure for more- and less-educated workers, as well as the observation that less-educated workers in the United States have experienced little growth in real wages in recent decades.

Our work could be extended in different directions. In our analysis, we focus on matchspecific investments that improve the productivity of a given worker-firm pair. One could also consider more general investments by firms in technologies that are complementary to workers' accumulated firm-specific skills. That is, while some firms' production technology relies on having experienced workers, other technologies work equally well with inexperienced workers. In a model of directed technological change along the lines of Acemoglu (2002b), the incentive to develop technologies that work well with experienced workers would be higher if (because of labor regulation) a firm is more likely to have many such workers in the future. The direction of technical change in the context of a search model has previously been considered by Michelacci and Lopez-Salido (2007), but not from the perspective of the skill premium in the labor market.

In terms of modeling workers' careers, a natural next step would be to consider a framework that allows for job-to-job transitions and job ladders (as in Moscarini and 
Postel-Vinay 2019). Job-to-job transitions do occur in our framework, because workers can quickly find a job after a separation. However, we do not focus on job-to-job transitions as a source of wage growth. Voluntary job-to-job transitions would naturally interact with firms' incentives to invest in the relationship. ${ }^{18}$

Our employment protection model focuses on blanket protections that apply to all workers and can be interpreted as government regulations. Another potential source of firing restrictions are unions. It would be interesting to relate the employment-protection mechanism to changes in the reach of unions over time and across countries (see, for example, Acemoglu, Aghion, and Violante 2001 for an analysis of the role of deunionzation for inequality). However, deunionization does not offer an immediate explanation for the object of study here, namely the different trends between the United States and Germany, since union coverage has fallen drastically since the 1980s in Germany (Dustmann, Ludsteck, and Schönberg 2009).

When comparing the skill transferability of more- and less-educated workers, the question of why college-educated workers have more portable skills is relevant. One possibility is that portable skills are ultimately linked to a worker's occupation, and college-educated workers have a higher likelihood of being able to continue in the same occupation after a layoff (Kambourov and Manovskii 2009b; Kambourov and Manovskii 2009a; Böhm, von Gaudecker, and Schran 2019).

Lastly, the creation of different types of jobs plays a central role in our theory, and it would be useful to provide more direct empirical evidence on what characterizes these job types. Along these lines, Gregory (2020) uses German data to document heterogeneity in the steepness of workers' earnings profiles across firms, which corresponds well with the two job types in our theory. Bayer and Kuhn (2019) consider the ability to transition into jobs that involve more responsibility to be an important source of wage growth. Type- $A$ jobs in our environment could be interpreted as settings were firms make such transitions possible. There can also be heterogeneity across jobs in terms of job security (Jarosch 2015, Jung and Kuhn 2018), which would naturally interact with the incentive to invest in the relationship-specific skills emphasized in our theory. In short, there are many opportunities for future research on the relationship between employment protection, investment in relationship-specific skills, and wage inequality in modern economies.

\footnotetext{
${ }^{18}$ See Lentz and Roys (2015) for an analysis that integrates job-to-job transitions with the issue of general job-specific training.
} 


\section{References}

Acemoglu, Daron. 1999. "Changes in Unemployment and Wage Inequality: an Alternative Theory and Some Evidence." American Economic Review 89 (5): 1259-1278.

—. 2002a. "Directed Technical Change." Review of Economic Studies 69 (4): 781-809.

_. 2002b. "Technical Change, Inequality, and the Labor Market." Journal of Economic Literature 40 (1): 7-72.

—. 2003. "Cross-Country Inequality Trends." Economic Journal 113:F121-F149.

Acemoglu, Daron, Philippe Aghion, and Giovanni L. Violante. 2001. "Deunionization, Technical Change and Inequality." Carnegie-Rochester Conference Series on Public Policy 55 (1): 229-264.

Acemoglu, Daron, and Jorn-Steffen Pischke. 1999a. "Beyond Becker: Training in Imperfect Labour Markets." The Economic Journal 109 (453): 112-142.

Acemoglu, Daron, and Jörn-Steffen Pischke. 1999b. "The Structure of Wages and Investment in General Training." Journal of Political Economy 107 (3): 539-572.

Acemoglu, Daron, and Pascual Restrepo. 2020. "Robots and Jobs: Evidence from US Labor Markets." Forthcoming, Journal of Political Economy.

Alon, Titan. 2017. "Earning More by Doing Less: Human Capital Specialization and the College Wage Premium." Unpublished Manuscript, Northwestern University.

Altonji, Joseph G., and Robert A. Shakotko. 1987. “Do Wages Rise with Job Seniority?" Review of Economic Studies 54 (3): 437-459.

Altonji, Joseph G., and Nicolas Williams. 2005. "Do Wages Rise with Job Seniority? A Reassessment." Industrial and Labor Relations Review 58 (3): 370-397.

Autor, David, and David Dorn. 2013. "The Growth of Low-Skill Service Jobs and the Polarization of the US Labor Market." American Economic Review 103 (5): 1553-97.

Autor, David, David Dorn, and Gordon H Hanson. 2013. "The China Syndrome: Local Labor Market Effects of Import Competition in the United States." American Economic Review 103 (6): 2121-68.

Autor, David H. 2019. "Work of the Past, Work of the Future." AEA Papers and Proceedings 109:1-32.

Autor, David H., Frank Levy, and Richard J. Murnane. 2003. "The Skill Content of Recent Technological Change: An Empirical Exploration." The Quarterly Journal of Economics 118 (4): 1279-1333. 
Bayer, Christian, and Moritz Kuhn. 2019. "Which Ladder to Climb? Decomposing Life Cycle Wage Dynamics." Unpublished Manuscript, University of Bonn.

Bentolila, Samuel, and Giuseppe Bertola. 1990. "Firing Costs and Labour Demand: How Bad is Eurosclerosis?" Review of Economic Studies 57 (3): 381-402.

Bertola, Giuseppe, and Andrea Ichino. 1995. "Wage Inequality and Unemployment: United States versus Europe." In NBER Macroeconomics Annual, edited by Ben S. Bernanke and Julio J. Rotemberg, 13-66. MIT Press.

Blanchard, Olivier J., and Lawrence H. Summers. 1986. "Hysteresis and the European Unemployment Problem." In NBER Macroeconomics Annual 1986, edited by Stanley Fischer, 15-90. MIT Press.

Böhm, Michael J., Hans-Martin von Gaudecker, and Felix Schran. 2019. “Occupation Growth, Skill Prices, and Wage Inequality." Unpublished Manuscript, University of Bonn.

Bratti, Massimiliano, Maurizio Conti, and Giovanni Sulis. 2018. "Employment Protection, Temporary Contracts and Firm-Provided Training: Evidence from Italy." IZA Discussion Paper 11339.

Buchinsky, Moshe, Denis Fougère, Francis Kramarz, and Rusty Tchernis. 2010. "Interfirm Mobility, Wages and the Returns to Seniority and Experience in the United States." Review of Economic Studies 77 (3): 972-1001.

Card, David, and Thomas Lemieux. 2001. "Can Falling Supply Explain the Rising Return to College for Younger Men? A Cohort-Based Analysis." Quarterly Journal of Economics 116 (2): 705-746.

Coile, Courtney, and Mark Duggan. 2019. “When Labor's Lost: Health, Family Life, Incarceration, and Education in a Time of Declining Economic Opportunity for Low-Skilled Men." Technical Report, National Bureau of Economic Research.

Dustmann, Christian, Johannes Ludsteck, and Uta Schönberg. 2009. "Revisiting the German Wage Structure." The Quarterly Journal of Economics 124 (2): 843-881.

Dustmann, Christian, and Costas Meghir. 2005. "Wages, Experience and Seniority." Review of Economic Studies 72 (1): 77-108.

Fuchs-Schündeln, Nicola, Dirk Krueger, and Mathias Sommer. 2010. "Inequality Trends for Germany in the Last Two Decades: A Tale of Two Countries." Review of Economic Dynamics 13 (1): 103-132. 
Gertler, Mark, and Antonella Trigari. 2009. “Unemployment Fluctuations with Staggered Nash Wage Bargaining." Journal of Political Economy 117 (1): 38-86.

Goldin, Claudia, and Lawrence F. Katz. 2008. The Race between Education and Technology. Cambridge, Massachusetts: The Belknap Press of Harvard University Press.

Gregory, Victoria. 2020. "Firms as Learning Environments: Implications for Earnings Dynamics and Job Search." Unpublished Manuscript, NYU.

Guvenen, Fatih, Greg Kaplan, Jae Song, and Justin Weidner. 2017. "Lifetime Incomes in the United States Over Six Decades." NBER Working Paper 23371.

Guvenen, Fatih, and Burhanettin Kuruscu. 2009. "A Quantitative Analysis of the Evolution of the U.S. Wage Distribution, 1970-2000." NBER Macroeconomics Annual 10 (3): 482-517.

Guvenen, Fatih, Burhanettin Kuruscu, and Serdar Ozkan. 2013. “Taxation of Human Capital and Wage Inequality: A Cross-Country Analysis." Review of Economic Studies 81 (2): 818-850.

Hall, Robert E. 1982. "The Importance of Lifetime Jobs in the U.S. Economy." American Economic Review 72 (4): 716-724.

Heathcote, Jonathan, Fabrizio Perri, and Giovanni L Violante. 2010. "Unequal We Stand: An Empirical Analysis of Economic Inequality in the United States, 1967-2006." Review of Economic Dynamics 13 (1): 15-51.

Heathcote, Jonathan, Kjetil Storesletten, and Giovannni L. Violante. 2010. “The Macroeconomic Implications of Rising Wage Inequality in the United States." Journal of Political Economy 118 (4): 681-722.

Hémous, David, and Morten Olsen. 2018. "The rise of the Machines: Automation, Horizontal Innovation and Income Inequality." Unpublished Manuscript, University of Zurich.

Hollister, Matissa. 2011. "Employment Stability in the US Labor Market: Rhetoric versus Reality." Annual Review of Sociology 37:305-324.

Hornstein, Andreas, Per Krusell, and Giovanni L. Violante. 2007. “Technology-Policy Interaction in Frictional Labour-Markets." Review of Economic Studies 74 (4): 10891124.

Hyatt, Henry R, and James R Spletzer. 2016. "The Shifting Job Tenure Distribution." Labour Economics 41:363-377. 
Jaimovich, Nir, Sergio Rebelo, Arlene Wong, and Miao Ben Zhang. 2019. “Trading Up and the Skill Premium." NBER Macro Annual.

Jappelli, Tullio, and Luigi Pistaferri. 2010. "Does Consumption Inequality Track Income Inequality in Italy?" Review of Economic Dynamics 13 (1): 133-153.

Jarosch, Gregor. 2015. "Searching for Job Security and the Consequences of Job Loss." Unpublished Manuscript, Princeton University.

Jung, Philip, and Moritz Kuhn. 2018. "Earnings Losses and Labor Mobility Over the Life Cycle." Journal of the European Economic Association 17 (3): 678-724.

Kambourov, Gueorgui, and Iourii Manovskii. 2009a. “Occupational Mobility and Wage Inequality." Review of Economic Studies 76 (2): 731-759 (04).

. 2009b. "Occupational Specificity of Human Capital." International Economic Review 50 (1): 63-115.

Katz, Lawrence F., and David H. Autor. 1999. "Changes in the Wage Structure and Earnings Inequality." Chapter Chapter 26 of Handbook of Labor Economics, Vol. 3, edited by Orley Ashenfelter, , and David Card. North Holland.

Katz, Lawrence F., and Kevin M. Murphy. 1992. "Changes in Relative Wages, 1963-1987: Supply and Demand Factors." Quarterly Journal of Economics 107 (1): 35-78.

Kitao, Sagiri, Lars Ljungqvist, and Thomas J. Sargent. 2017. "A Life-cycle Model of Trans-Atlantic Employment Experiences." Review of Economic Dynamics 25:320-49.

Kletzer, Lori G. 1989. "Returns to Seniority After Permanent Job Loss." American Economic Review 79 (3): 536-543.

Kletzer, Lori G. 1998. "Job Displacement." Journal of Economic Perspectives 12 (1): 115-136.

Krueger, Dirk, Fabrizio Perri, Luigi Pistaferri, and Giovanni L. Violante. 2010. “Crosssectional Facts for Macroeconomists." Review of Economic Dynamics 13 (1): 1-14. Special issue: Cross-Sectional Facts for Macroeconomists.

Krusell, Per, Lee E Ohanian, José-Víctor Ríos-Rull, and Giovanni L Violante. 2000. "Capital-Skill Complementarity and Inequality: A Macroeconomic Analysis." Econometrica 68 (5): 1029-1053.

Lentz, Rasmus, and Nicolas Roys. 2015, November. "Training and Search On the Job." NBER Working Paper 21702.

Ljungqvist, Lars, and Thomas J. Sargent. 1998. "The European Unemployment Dilemma." Journal of Political Economy 106 (3): 514-550. 
Michelacci, Claudio, and David Lopez-Salido. 2007. “Technology Shocks and Job Flows." Review of Economic Studies 74 (4): 1195-1227.

Molloy, Raven, Christopher L. Smith, and Abigail Wozniak. 2019. “Changing Stability in U.S. Employment Relationships: A Tale of Two Tails." Unpublished Manuscript, Federal Reserve Bank of Minneapolis.

Moscarini, Giuseppe, and Fabien Postel-Vinay. 2019. "The Job Ladder: Inflation vs. Reallocation." Unpublished Manuscript, Yale University.

Nickell, Stephen. 1997. “Unemployment and Labor Market Rigidities: Europe versus North America." Journal of Economic Perspectives 11 (3): 55-74.

Pries, Michael J, and Richard Rogerson. 2019. "Declining Worker Turnover: the Role of Short Duration Employment Spells." NBER Working Paper 26019.

Segal, Lewis M, and Daniel G Sullivan. 1997. "The Growth of Temporary Services Work." Journal of Economic Perspectives 11 (2): 117-136.

Valletta, Robert G. 2016. “Recent Flattening in the Higher Education Wage Premium: Polarization, Skill Downgrading, or Both?" NBER Working Paper 22935.

Wasmer, Etienne. 2006. "General versus Specific Skills in Labor Markets with Search Frictions and Firing Costs." American Economic Review 96 (3): 811-831.

\section{A Data Appendix}

The main data sources for the empirical analysis and the model calibration are the Panel Study of Income Dynamics for the United States, and the Socio-Economic Panel (GSOEP) for Germany. The PSID is conducted by the Survey Research Center (SRC) at the University of Michigan and can be accessed freely via their website. ${ }^{19}$ The GSOEP is administered by the German Institute for Economic Research, DIW Berlin. More information on the GSOEP and how researchers can gain access to it is available on the Institute's website. ${ }^{20}$

Panel Study of Income Dynamics The PSID was conducted on a yearly basis between 1968 and 1996, and every two years from 1997 onwards. The structure of the PSID is a panel in which individuals belonging to a PSID family in 1968 are followed over time

\footnotetext{
${ }^{19}$ https://psidonline.isr.umich.edu/default.aspx

${ }^{20}$ https://www.diw.de/en/soep
} 
as they form a new household or re-join their previous one. We focus on individuals in families belonging to the original SRC sample, which is designed to be representative of the US population.

We focus on male respondents who, at the time of the interview, are identified as their family's head. ${ }^{21}$ For consistency with the assumptions on demographics in the model, we restrict attention to individuals aged 25-64 who declare that they only work for someone else. Hence, we exclude self-employed individuals and those who answer that they work for "Both someone else and self."

We define a single education variable for each individual that corresponds to the maximum reported educational attainment, or the maximum number of years of education. Workers are classified as having a high-school degree if they report at least 12 but less than 16 years of education, and as having a college degree if they report at least 16 years of education. We discard individuals with less than 12 years of education. We define real earnings per hour as earnings per hour deflated via the CPI, using 2010 as base year. We discard observations where the resulting real hourly earnings are below 7.502010 dollars, or the total number of hours worked is below 500 or above 5,000 in the last year.

Potential experience is defined as current age minus (years of education +6 ). The employment tenure variable is continuously available starting from 1981. Until 1993, the information is reported as the number of months with the current employer. From 1994 onwards, the information is reported in three separate questions for years, months, and weeks with the current employer, which must be added to obtain a single tenure figure. To maintain consistency with the quantitative model, we then adjust the tenure figure by taking the minimum between the tenure information and age -25 . We discard observations for which the resulting months of tenure are more than $12 \times($ age -16$)$.

All the statistics in the paper are computed using a system of weights that keeps the age distribution constant in every year to the 1981 distribution.

Socio-Economic Panel The German GSOEP has been conducted on a yearly basis since 1984. Similarly to the PSID, the GSOEP is a longitudinal study that periodically surveys the same set of families that were interviewed in the original sample. Although there have been expansions in the samples in 1990 (East German sample) and in 1994 (immigrant

\footnotetext{
${ }^{21}$ The PSID reports that: "Historically, PSID has used the term Head to refer to the husband in a heterosexual married couple and to a single adult of either sex. Starting in 2017, the term "Reference Person" replaced "Head." For more information visit: https://psidonline.isr.umich.edu/Guide/FAQ.aspx.
} 
sample), we focus on the original sample, which only includes families originally from West Germany.

We focus on male respondents aged 25-64 who do not declare themselves to be selfemployed. We infer self-employment from the "generated" variable labeled "STIB Occupational Position."

The GSOEP provides separate variables for college attainment and total years of education and training. We define a college degree variable for each individual if college completion is reported at some point in the panel. For those who do not report college completion, we define a unique educational attainment variable for each individual, based on the highest number of years of education recorded in the panel for that individual. We then generate a high-school degree variable if the individual reports at least 10.5 years of education or training. We discard observations that report less than 10.5 years of education or training.

We discard workers who declare less than 20 hours of work per week. We postulate a minimum hourly wage that is equal, in every year, to the 2015 statutory minimum wage (8.50 euros per hour), discounted by the relative price index.

Starting with the system of individual weights provided by the GSOEP for the original sample, we construct a system of weights that keeps the age distribution constant over the years to the 1984 distribution, in an analogous manner to the US sample.

\section{B Model Computation}

In computing the model, we impose a vector of 20 possible values for individual human capital, $h, \log$-spaced between $h_{1}=1$ and $h_{20}=20$. We discretize the vector of turbulence shocks, $\epsilon$, as 10 equally spaced values between 0.01 and $\bar{\epsilon}=0.6$.

The calibration routine minimizes a loss function defined, for each vector of parameters $p$, as the sum of the squared differences between the data-generated and the modelgenerated moment:

$$
\min L(p)=\sum_{m} a_{m}\left[\operatorname{Data}_{m}-\operatorname{Model}_{m}(p)\right]^{2} .
$$

where the weight $a_{m}$ is set equal to 10 for the moments that concern the fraction of workers with short- and long-term tenure (which is particularly important to match given our mechanism), and equal to one for the other moments. 


\section{Additional Figures and Tables}

\begin{tabular}{lcc}
\hline \hline & \multicolumn{2}{c}{ Log of hourly wage (ages 45-54) } \\
\hline & US $(1981-2013)$ & DE $(1984-2013)$ \\
\hline Tenure $>=20$ & $0.281^{* * *}$ & $0.122^{* * *}$ \\
College graduate & $(.030)$ & $(.021)$ \\
& $0.488^{* * *}$ & $0.475^{* * *}$ \\
Interaction & $(.035)$ & $(.053)$ \\
& $-.107^{* *}$ & $-.166^{* * *}$ \\
\hline Exper. 3rd degree pol. & $(.048)$ & $(.050)$ \\
Year FE & yes & yes \\
\hline \# Obs. & yes & yes \\
$R^{2}$ & 7,578 & 10,137 \\
\hline
\end{tabular}

Notes: Standard errors clustered at individual level in parentheses. For the PSID, the sample consists of male workers aged 45 to 54 who report between 500 and 5,000 hours worked in a year. For the GSOEP, the sample consists of male workers aged 45 to 54 who report a minimum of 20 hours worked per week in the last year. Each column consists of a separate regression of log wages on a year fixed effect, a third-degree polynomial of potential experience, and an indicator variable for 20 years of tenure or more on the current job. ${ }^{* *} p<0.01$, ${ }^{* *} \mathrm{p}<0.05,{ }^{*} \mathrm{p}<0.1$.

Table 12: Returns to high tenure for college- and less-educated workers in the US (PSID) and Germany (GSOEP). 


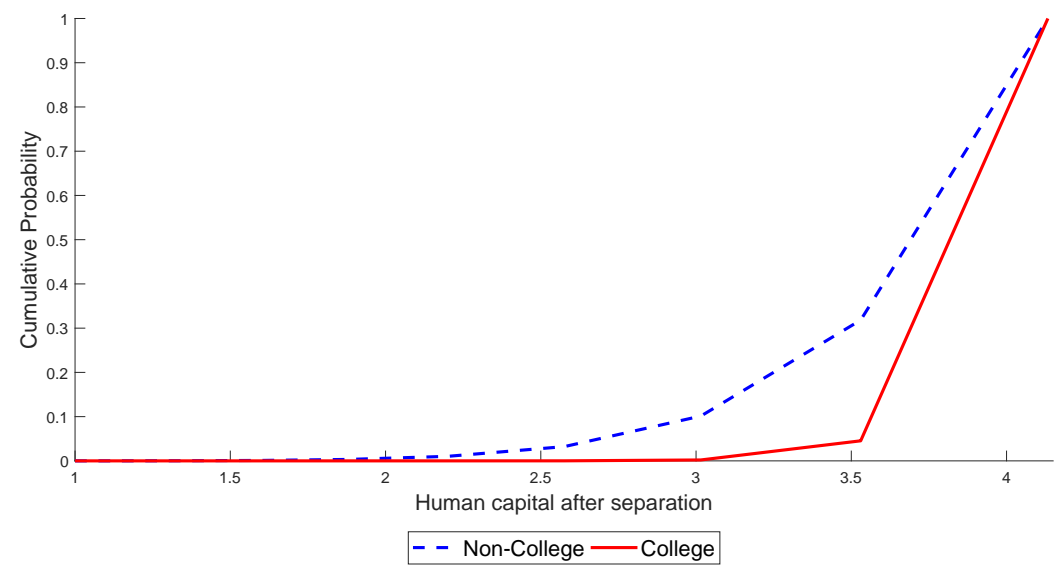

Figure 10: Cumulative probability of falling to any skill level $h^{\prime}$ after a separation with skill level $h=h_{10}$ for $L$ (dotted line) and $H$ (solid line) workers.

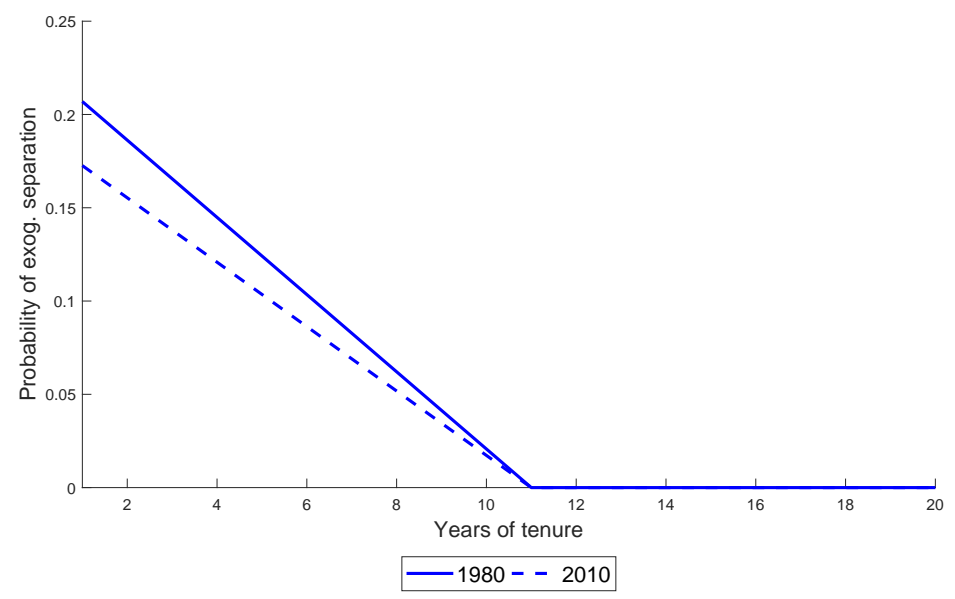

Figure 11: Probability of exogenous separation as a function of tenure for $L$ and $H$ workers in the 1980 (solid line) and 2010 (dotted line) calibrations. 

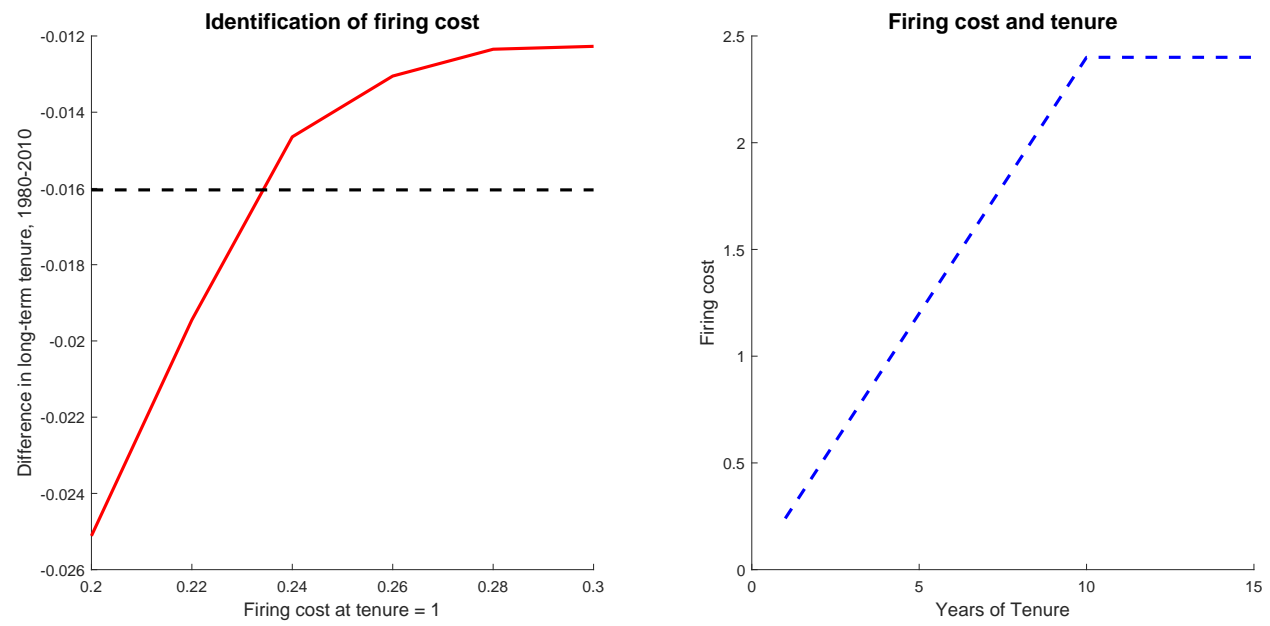

Figure 12: Left panel: Difference in the share of long-term tenure workers in Germany and the US as a function of the firing cost, and difference in the data (dotted black line). Right panel: Calibrated firing cost as a function of years of tenure with current employer. 